\title{
Myrsinane, Premyrsinane, and Cyclomyrsinane Diterpenes from Euphorbia falcata as Potassium lon Channel Inhibitors with Selective G Protein-Activated Inwardly Rectifying lon Channel (GIRK) Blocking Effects
}

\author{
Andrea Vasas, ${ }^{\dagger}$ Peter Forgo, ${ }^{\dagger}$ Péter Orvos, ${ }^{\ddagger}$, László Tálosi, $^{\ddagger}$ Attila Csorba, ${ }^{\dagger}$ Gyula Pinke, ${ }^{\perp}$ \\ and Judit Hohmann*, ${ }^{\dagger}, \|$ \\ ${ }^{\dagger}$ Department of Pharmacognosy and "Interdisciplinary Centre for Natural Products, University of Szeged, Eötvös u. 6, H-6720 \\ Szeged, Hungary \\ ${ }^{\ddagger}$ Rytmion Ltd., Ősz u. 27, H-6724 Szeged, Hungary \\ ${ }^{\S}$ Department of Pharmacology and Pharmacotherapy, University of Szeged, Dóm tér 12, H-6720 Szeged, Hungary \\ ${ }^{\perp}$ Department of Botany, Faculty of Agricultural and Food Sciences, Széchenyi István University, Vár 2, H-9200 Mosonmagyaróvár, \\ Hungary
}

Supporting Information

ABSTRACT: GIRK channels are activated by a large number of $\mathrm{G}$ protein-coupled receptors and regulate the electrical activity of neurons, cardiac atrial myocytes, and $\beta$-pancreatic cells. Abnormalities in GIRK channel function have been implicated in the pathophysiology of neuropathic pain, drug addiction, and cardiac arrhythmias. In the heart, GIRK channels are selectively expressed in the atrium, and their activation inhibits pacemaker activity, thereby slowing the heart rate. In the present study, 19 new diterpenes, falcatins $A-S$ (1-19), and the known euphorprolitherin D (20) were isolated from Euphorbia falcata. The compounds were assayed on stable transfected HEK-hERG (Kv11.1) and HEK-GIRK1/4 (Kir3.1 and Kir3.4) cells. Blocking activity on GIRK channels was exerted by 13 compounds (61-
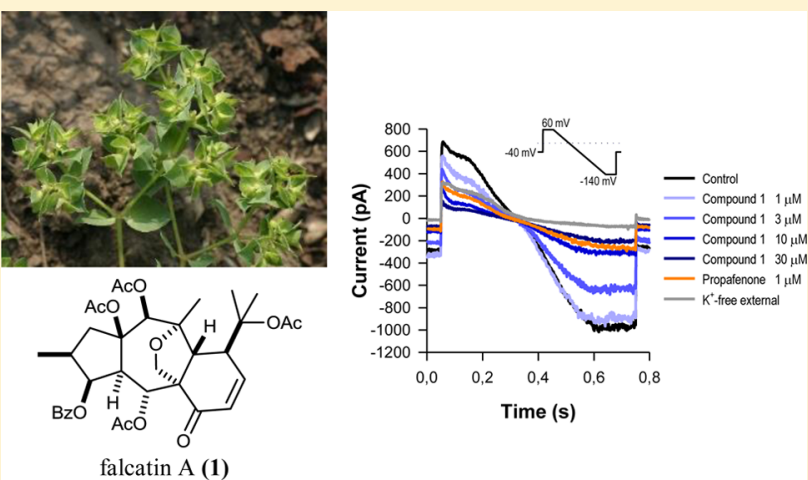

falcatin A (1) $83 \%$ at $10 \mu \mathrm{M})$, and, among them, five possessed low potency on the hERG channel $(4-20 \%$ at $10 \mu \mathrm{M})$. These selective activities suggest that myrsinane-related diterpenes are potential lead compounds for the treatment of atrial fibrillation.

ardiovascular diseases are the leading cause of death and
loss of disability-adjusted life-years worldwide. ${ }^{1}$ A notable
portion of such diseases are linked to the dysfunction of cardiac
ion channels. Ion channels are a large and diverse family of
transmembrane pore-forming proteins. ${ }^{2-8}$ These proteins
facilitate the rapid passive transport of specific inorganic ions
(such as $\mathrm{Na}^{+}, \mathrm{K}^{+}, \mathrm{Ca}^{2+}$, and $\mathrm{Cl}^{-}$) through the lipid bilayers of
plasma and organelle membranes down their electrochemical
gradient that is established by the work of pumps and
transporters. ${ }^{2,6-10}$ Defined by the stimulus necessary to evoke
activity, the majority of ion channels are classified commonly into
two main subgroups: voltage-gated and ligand-gated channels.
The most important difference is that voltage-gated ion channels
are activated by changes in plasma membrane potential, while
ligand-gated channels are activated by endogenous ligands.
Ion channels are also grouped into various subclasses by another
key functional characteristic, their selective permeability to
different ions. ${ }^{8,9,12}$ Voltage-gated ion channels are rather specific
for the various cations and anions. Therefore, these channels are typically named after the ion for which they are selective. Several classes of potassium channels play an important role in the regulation of function of the myocardium.

GIRK channels ( $G$ protein-activated inwardly rectifying potassium ion channels) are involved in the regulation of the electrical activity of neurons, cardiac atrial myocytes, and $\beta$ pancreatic cells. Abnormalities in GIRK channel function have been implicated in the pathophysiology of neuropathic pain, drug addiction, cardiac arrhythmias, and other disorders. ${ }^{13}$ In the heart muscles, GIRK potassium channels are selectively expressed in the cardiac atrium, activated by a large number of $G$ proteincoupled receptors and responsible for $\mathrm{K}^{+}$-fluxes and membrane repolarization and/or hyperpolarization. Electrical remodeling of atrial heart muscle during chronic atrial fibrillation may result in a constitutively active form of the GIRK channel, which may lead to an important role of this channel in this disease. Selective

Received: March 22, 2016 
inhibition of myocardial GIRK channels in animal atrial fibrillation models reduces the number of provoked atrial fibrillation episodes and decreases the duration of these arrhythmic periods. Therefore, selective blockade of the GIRK channel might be a useful tool in the treatment of atrial fibrillation, and these channels are novel targets in the search for new antiarrhythmic agents. ${ }^{14-16}$

hERG channels (human ether-a-go-go-related gene encoded potassium channels) are $\mathrm{K}^{+}$-selective voltage-gated ion channels, belonging to the $\mathrm{Kv}$ channel family, also referred to as Kv11.1. hERG channels mediate the rapid delayed rectifier $\mathrm{K}^{+}$current $\left(I_{\mathrm{Kr}}\right)$ in ventricular myocytes and are expressed in both the atrium and ventricle. These channels can be blocked by chemicals with diverse structures that encompass several therapeutic drug classes, including antiarrhythmics, psychiatric agents, antimicrobials, and antihistamines. ${ }^{17}$ Compounds with hERG-blocking activity may modify the action potential of the heart muscle, which can lead to prolongation of the action potential and an increased risk of severe ventricular arrhythmias such as ventricular fibrillation and sudden cardiac death. hERG-blocking activity has been the reason for the withdrawal of several wouldbe "blockbuster" drugs from the market. At present, every new drug must go through preclinical safety testing determined by the U.S. Food and Drug Administration, the European Medicines Agency, and other regulatory entities. $2,3,5,8,18-20$

For many years natural products have made a major impact in the treatment of cardiovascular diseases. More recently, a number of bioactive compounds generally obtained from terrestrial plants such as carotenoids, catechin, isoflavones, quercetin, resveratrol, sulforaphane, and tocotrienols have been proven to promote cardioprotection and to reduce the risk of cardiovascular diseases. ${ }^{21}$ Great efforts are ongoing worldwide in the search for new natural compounds that can selectively influence these diseases.

Plants in the genus Euphorbia are well known for the chemical diversity of their diterpenoids. Several of them are of particular interest because of their restricted occurrence and broad structural diversity, as a consequence of different frameworks such as jatrophanes, tiglianes, ingenanes, lathyranes, myrsinanes, and daphnanes. ${ }^{22}$ Previous studies have indicated that diterpenes of Euphorbia species have a wide variety of biological activities, such as skin-irritant, antiproliferative, cytotoxic, and antiviral properties and multidrug resistance modulating and antiinflammatory effects. ${ }^{22-24}$ However, no data have been reported concerning the potential cardiac effects of this type of natural compound.

As a part of our research program to discover new bioactive compounds from Euphorbia species, the chloroform-soluble fraction of a methanol extract of Euphorbia falcata L. (Euphorbiaceae) was investigated. This study resulted in the isolation and structure determination from this plant of 19 new diterpenes (falcatins $A-S, 1-19$ ) and one known diterpene (euphorprolitherin D, 20) based on myrsinane, premyrsinane, and cyclomyrsinane skeletons. These compounds together with four premyrsinane and cyclomyrsinane-type diterpenes (2124), ${ }^{25,26}$ isolated earlier from this plant by our group, were studied for their GIRK- and hERG channel-inhibitory activities using an automated patch-clamp method.

\section{RESULTS AND DISCUSSION}

Twenty diterpenes $(\mathbf{1 - 2 0})$ were isolated from the $\mathrm{CHCl}_{3}$ soluble phase of the $\mathrm{MeOH}$ extract prepared from the whole plant of E. falcata by a combination of different chromatographic methods, such as CC, VLC, CPC, preparative TLC, and HPLC. The structure elucidation was carried out by spectroscopic analysis, including $1 \mathrm{D}$ and $2 \mathrm{D}$ NMR $\left({ }^{1} \mathrm{H}-{ }^{1} \mathrm{H}\right.$ COSY, HSQC, HMBC, and NOESY) and HRESIMS experiments. The NMR data showed that all compounds are myrsinane-related diterpenes (myrsinanes, premyrsinanes, and cyclomyrsinanes).
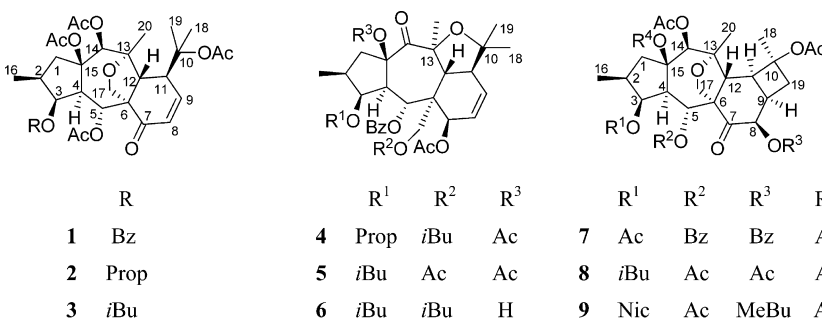

$\begin{array}{cccc} & \mathrm{R}^{1} & \mathrm{R}^{2} & \mathrm{R}^{3} \\ \mathbf{4} & \text { Prop } & i \mathrm{Bu} & \mathrm{Ac} \\ \mathbf{5} & i \mathrm{Bu} & \mathrm{Ac} & \mathrm{Ac} \\ \mathbf{6} & i \mathrm{Bu} & i \mathrm{Bu} & \mathrm{H}\end{array}$

$\begin{array}{rcccl} & \mathrm{R}^{1} & \mathrm{R}^{2} & \mathrm{R}^{3} & \mathrm{R}^{4} \\ \mathbf{7} & \mathrm{Ac} & \mathrm{Bz} & \mathrm{Bz} & \mathrm{Ac} \\ \mathbf{8} & i \mathrm{Bu} & \mathrm{Ac} & \mathrm{Ac} & \mathrm{Ac} \\ \mathbf{9} & \mathrm{Nic} & \mathrm{Ac} & \mathrm{MeBu} & \mathrm{Ac} \\ \mathbf{2 0} & \text { Prop } & \mathrm{Ac} & \mathrm{Bz} & \mathrm{H}\end{array}$
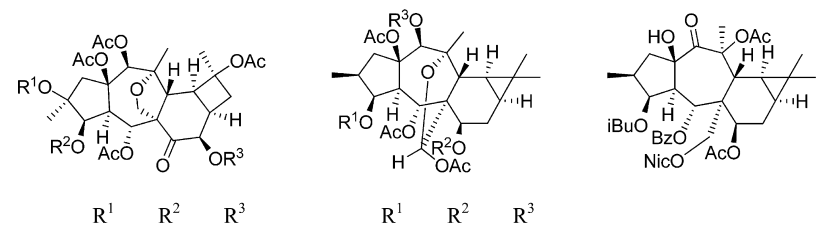

$10 \mathrm{H}$ Prop $\mathrm{MeBu}$

$11 \mathrm{H} \quad i \mathrm{Bu} \quad \mathrm{MeBu}$

$12 \mathrm{Nic} i \mathrm{Bu} \mathrm{MeBu}$

$13 \mathrm{Nic} i \mathrm{Bu} i \mathrm{Bu}$

14 Nic Prop $i$ Bu

15 Bz Prop $\mathrm{MeBu}$

$$
\begin{array}{llll} 
& \mathrm{R}^{1} & \mathrm{R}^{2} & \mathrm{R}^{3} \\
\mathbf{1 6} & i \mathrm{Bu} & \mathrm{Bz} & \mathrm{Ac} \\
\mathbf{1 7} & i \mathrm{Bu} & \mathrm{Nic} & \mathrm{Bz} \\
\mathbf{1 8} & \text { Prop } & \text { Nic } & \mathrm{Bz}
\end{array}
$$

Characterization of Compounds $1-19$. Compound 1 was obtained as an amorphous solid with $[\alpha]^{25}-8\left(c 0.2, \mathrm{CHCl}_{3}\right)$. Its HRESIMS provided the molecular formula, $\mathrm{C}_{35} \mathrm{H}_{42} \mathrm{O}_{12}$, through the presence of a peak at $\mathrm{m} / z 677.2594[\mathrm{M}+\mathrm{Na}]^{+}$ (calcd for $\mathrm{C}_{35} \mathrm{H}_{42} \mathrm{O}_{12} \mathrm{Na}, 677.2574$ ). The ${ }^{1} \mathrm{H}$ and ${ }^{13} \mathrm{C} \mathrm{NMR}$ spectra of 1 revealed the presence of four acetyl groups $\left[\delta_{\mathrm{H}} 1.97 \mathrm{~s}\right.$, $2.01 \mathrm{~s}, 2.06$, and $2.16 \mathrm{~s} ; \delta_{\mathrm{C}} 170.5,169.2,170.1$, and $168.3(\mathrm{CO})$ and 22.4, 21.1, 21.0, and $\left.23.2\left(\mathrm{CH}_{3}\right)\right]$ and one benzoyl substituent $\left[\delta_{\mathrm{H}} 7.94 \mathrm{~d}, 7.40\right.$ and $7.53 \mathrm{t} ; \delta_{\mathrm{C}} 166.8,129.3,128.0$, 132.6, and 131.0] (Tables 1 and 2). Additionally, the ${ }^{1} \mathrm{H}$ NMR

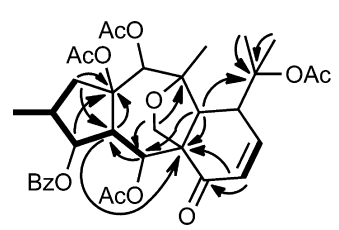

Figure 1. Selected ${ }^{1} \mathrm{H}-{ }^{1} \mathrm{H}$ COSY (bold) and $\operatorname{HMBC}(\mathrm{C} \rightarrow \mathrm{H})$ correlations for 1 .

spectrum exhibited signals attributed to skeletal protons, including four methyls $(0.88 \mathrm{~d}, 1.59 \mathrm{~s}, 1.45 \mathrm{~s}$, and $1.24 \mathrm{~s})$. The ${ }^{1} \mathrm{H}-{ }^{1} \mathrm{H}$ COSY spectrum defined two structural fragments with correlated protons: $-\mathrm{CH}_{2}-\mathrm{CH}\left(\mathrm{CH}_{3}\right)-\mathrm{CHR}-\mathrm{CH}-\mathrm{CHR}-(\mathrm{A})$ $\left(\delta_{\mathrm{H}} 2.83,2.61,2.27,5.63,3.15\right.$, and 6.00$)$ and $-\mathrm{CH}=\mathrm{CH}-(\mathrm{B})$ $\left(\delta_{\mathrm{H}} 6.19\right.$ and 6.54$)$. These two structural parts and the tertiary methyls and quaternary carbons were connected by inspection of the long-range $\mathrm{C}-\mathrm{H}$ correlations observed in the $\mathrm{HMBC}$ spectrum (Figure 1). The two- and three-bond correlations between the quaternary carbon $\mathrm{C}-15$ and $\mathrm{H}-1, \mathrm{H}-3$, and $\mathrm{H}-4$ and between $\mathrm{C}-4$ and $\mathrm{H}-1$ and $\mathrm{H}-5$ revealed that structural fragment A together with $\mathrm{C}-15$ forms a five-membered ring, present in many types of Euphorbiaceae diterpenes. HMBC cross-peaks 
Table 1. ${ }^{1} \mathrm{H}$ NMR Data $\left(\delta_{\mathrm{H}}\right)$ of Compounds 1-6 $\left[\delta \mathrm{ppm}(J=\mathrm{Hz}), \mathrm{CDCl}_{3}, 500 \mathrm{MHz}\right]$

\begin{tabular}{|c|c|c|c|c|c|c|}
\hline position & 1 & 2 & 3 & 4 & 5 & 6 \\
\hline $1 \alpha$ & 2.83, dd $(15.8,10.9)$ & $2.80, \mathrm{dd}(15.8,9.8)$ & 2.76 , dd $(15.8,10.9)$ & 3.06 , dd $(14.5,9.0)$ & $3.14, \mathrm{dd}(14.4,5.6)$ & $2.92, \mathrm{~m}$ \\
\hline $1 \beta$ & $2.61, \mathrm{dd}(15.8,9.1)$ & 2.50 , dd $(15.8,9.3)$ & $2.54, \mathrm{~m}$ & 1.75 , dd $(14.5,9.2)$ & 1.76, dd $(14.4,10.1)$ & 1.75 , dd $(14.5,9.3)$ \\
\hline 2 & $2.27, \mathrm{~m}$ & $2.18, \mathrm{~m}$ & $2.16, \mathrm{~m}$ & $2.13, \mathrm{~m}$ & $2.15, \mathrm{~m}$ & $2.09, \mathrm{~m}$ \\
\hline 3 & $5.63, \mathrm{t}(3.8)$ & $5.41, \mathrm{t}(3.4)$ & $5.39, \mathrm{t}(3.5,3.2)$ & $5.51, \mathrm{t}(4.4)$ & $5.53, \mathrm{t}(4.1)$ & $5.55, \mathrm{t}(3.8)$ \\
\hline 4 & 3.15 , dd $(10.9,3.7)$ & 3.00 , dd $(10.8,3.4)$ & 3.01 , dd $(10.9,3.6)$ & $2.91, \mathrm{~m}$ & 2.84 , dd $(11.0,4.2)$ & 3.04 , dd $(11.1,3.8)$ \\
\hline 5 & $6.00, \mathrm{~d}(10.9)$ & $5.92, \mathrm{~d}(10.8)$ & $5.90, \mathrm{~d}(10.9)$ & $6.50, \mathrm{~d}(11.3)$ & $6.49, \mathrm{~d}(11.1)$ & $6.48, \mathrm{~d}(11.1)$ \\
\hline 7 & & & & $5.16, \mathrm{~d}(5.3)$ & $5.21, \mathrm{~d}(5.3)$ & $5.07, \mathrm{~d}(5.3)$ \\
\hline 8 & $6.19, \mathrm{~d}(10.3)$ & $6.22, \mathrm{~d}(10.3)$ & $6.20, \mathrm{~d}(10.2)$ & $6.01, \mathrm{~m}$ & $6.04, \mathrm{~m}$ & $6.02, \mathrm{~m}$ \\
\hline 9 & 6.54 , dd $(10.3,6.2)$ & 6.57 , dd $(10.3,6.4)$ & 6.55 , dd $(10.2,6.3)$ & 5.87 , dd $(9.8,1.9)$ & $5.87, \mathrm{~d}(9.8)$ & $5.84, \mathrm{~d}(9.8)$ \\
\hline 11 & $3,07, \mathrm{brm}$ & $3.06, \mathrm{brm}$ & $3.03, \mathrm{brm}$ & $2.91, \mathrm{~m}$ & $2.88, \mathrm{~d}(12.8)$ & $2.92, \mathrm{~m}$ \\
\hline 12 & $3.58, \mathrm{~s}$ & $3.54, \mathrm{~s}$ & $3.53, \mathrm{~s}$ & $3.45, \mathrm{~d}(12.7)$ & $3.42, \mathrm{~d}(12.8)$ & $3.20, \mathrm{~d}(12.7)$ \\
\hline 14 & $5.13, \mathrm{~s}$ & $5.08, \mathrm{~s}$ & $5.06, \mathrm{~s}$ & & & \\
\hline 16 & $0.88, \mathrm{~d}(6.8)$ & $0.84, \mathrm{~d}(6.8)$ & $0.82, \mathrm{~d}(6.8)$ & $0.92, \mathrm{~d}(6.9)$ & $0.88, \mathrm{~d}(7.0)$ & $0.90, \mathrm{~d}(6.8)$ \\
\hline \multirow[t]{2}{*}{17} & $4.31, \mathrm{~d}(9.1)$ & $4.28, \mathrm{~d}(9.0)$ & $4.26, \mathrm{~d}(9.1)$ & $4.48, \mathrm{~d}(12.1)$ & $4.59, \mathrm{~d}(12.1)$ & $4.50, \mathrm{~d}(12.0)$ \\
\hline & $3.87, \mathrm{~d}(9.1)$ & $3.87, \mathrm{~d}(9.0)$ & $3.84, \mathrm{~d}(9.1)$ & $4.29, \mathrm{~d}(12.1)$ & $4.12, \mathrm{~d}(12.1)$ & $4.32, \mathrm{~d}(12.0)$ \\
\hline 18 & $1.59, \mathrm{~s}$ & $1.59, \mathrm{~s}$ & $1.57, \mathrm{~s}$ & $1.04, \mathrm{~s}$ & $1.03, \mathrm{~s}$ & $1.06, \mathrm{~s}$ \\
\hline 19 & $1.45, \mathrm{~s}$ & $1.46, \mathrm{~s}$ & $1.45, \mathrm{~s}$ & $1.44, \mathrm{~s}$ & $1.43, \mathrm{~s}$ & $1.45, \mathrm{~s}$ \\
\hline 20 & $1.24, \mathrm{~s}$ & $1.23, \mathrm{~s}$ & $1.22, \mathrm{~s}$ & $1.57, \mathrm{~s}$ & $1.60, \mathrm{~s}$ & $1.54, \mathrm{~s}$ \\
\hline \multicolumn{7}{|l|}{$\mathrm{OiBu}-3$} \\
\hline 2 & & & 2.58 , sept (7.0) & & $2.43, \mathrm{~m}$ & 2.47 , sept (7.0) \\
\hline 3 & & & $1.18, \mathrm{~d}(7.0)$ & & $1.13, \mathrm{~d}(7.1)$ & $1.14, \mathrm{~d}(7.1)$ \\
\hline 4 & & & $1.18, \mathrm{~d}(7.0)$ & & $0.93, \mathrm{~d}(7.0)$ & $0.99, \mathrm{~d}(6.9)$ \\
\hline \multicolumn{7}{|l|}{ OProp-3 } \\
\hline 2 & & $2.43, \mathrm{dq}, 2.31, \mathrm{dq}(16.6,7.8)$ & & $2.22, \mathrm{~m}(2 \mathrm{H})$ & & \\
\hline 3 & & $1.16, \mathrm{t}(7.8)$ & & $0.94, \mathrm{t}(7.2)$ & & \\
\hline OAc-5 & $2.01, \mathrm{~s}$ & $2.03, \mathrm{~s}$ & $2.01, \mathrm{~s}$ & & $2.24, \mathrm{~s}$ & \\
\hline OAc-7 & & & & $2.24, \mathrm{~s}$ & & $2.17, \mathrm{~s}$ \\
\hline OAc-10 & $1.97, \mathrm{~s}$ & $2.02, \mathrm{~s}$ & $2.00, \mathrm{~s}$ & & & \\
\hline OAc-14 & $2.06, \mathrm{~s}$ & $2.06, \mathrm{~s}$ & $2.04, \mathrm{~s}$ & & & \\
\hline OAc- 15 & $2.16, \mathrm{~s}$ & $2.10, \mathrm{~s}$ & $2.09, \mathrm{~s}$ & $2.22, \mathrm{~s}$ & $2.22, \mathrm{~s}$ & \\
\hline OAc-17 & & & & & $1.54, \mathrm{~s}$ & \\
\hline \multicolumn{7}{|l|}{ OiBu-17 } \\
\hline 2 & & & & 2.09, sept $(6.8)$ & & $2.20, \mathrm{~m}$ \\
\hline 3 & & & & $0.96, \mathrm{~d}(6.8)$ & & $0.99, \mathrm{~d}(6.9)$ \\
\hline 4 & & & & $0.93, \mathrm{~d}(6.9)$ & & $0.95, \mathrm{~d}(6.9)$ \\
\hline \multicolumn{7}{|l|}{$\mathrm{OBz}$} \\
\hline 2,6 & $7.94, \mathrm{~d}(7.0)$ & & & $7.88, \mathrm{~d}(7.1)$ & $7.89, \mathrm{~d}(7.3)$ & $7.88, \mathrm{~d}(7.4)$ \\
\hline 3,5 & $7.40, \mathrm{t}(7.8)$ & & & $7.39, \mathrm{t}(7.8)$ & $7.54, \mathrm{t}(7.4)$ & $7.39, \mathrm{t}(7.6)$ \\
\hline 4 & $7.53, \mathrm{t}(7.5)$ & & & $7.53, \mathrm{t}(7.5)$ & $7.40, \mathrm{t}(7.7)$ & $7.53, \mathrm{t}(7.3)$ \\
\hline $\mathrm{OH}-15$ & & & & & & $2.83, \mathrm{~s}$ \\
\hline
\end{tabular}

between $\mathrm{C}-6$ and $\mathrm{H}-4, \mathrm{H}-8$, and $\mathrm{H}-12$, between $\mathrm{C}-7$ and $\mathrm{H}-8$, and between $\mathrm{C}-10$ and $\mathrm{H}-12, \mathrm{H}-18$, and $\mathrm{H}-19$ established a 10,18dihydromyrsinol-type diterpene with $\mathrm{O}$-functionalities at C-3, C5, C-7, C-10, C-14, and C-15. Moreover, the heteronuclear longrange coupling between $\mathrm{C}-5$ and $\mathrm{H}-17$ and $\mathrm{H}-12$, C-6 and $\mathrm{H}-17$ and $\mathrm{H}-12$, and between $\mathrm{C}-13$ and $\mathrm{H}-17$ indicated an O-bridge between $\mathrm{C}-17$ and $\mathrm{C}-13$, which is characteristic of many myrsinane, cyclomyrsinane, and premyrsinane polyesters. The positions of the ester groups were established via the HMBC experiment. The correlations of the carbonyl signal at $\delta_{\mathrm{C}} 169.2$ with the proton signal at $\delta_{\mathrm{H}} 6.00(\mathrm{H}-5)$ and the acetyl methyl signal at $\delta_{\mathrm{H}} 2.01$, and the carbonyl signal at $\delta_{\mathrm{C}} 170.1$ with the proton signal at $\delta_{\mathrm{H}} 5.13(\mathrm{H}-14)$ and the acetyl methyl signal at $\delta_{\mathrm{H}}$ 2.06 , indicated the presence of two acetyl groups at C-5 and C14. Similarly, the HMBC cross-peak of the signal at $\delta_{\mathrm{C}} 166.8$ (benzoyl CO) with the proton signals at $\delta_{\mathrm{H}} 5.63(\mathrm{H}-3)$ demonstrated the presence of the benzoyl group at C-3. The acetyl group at $\mathrm{C}-15$ was indicated by the weak four-bond $\mathrm{HMBC}$ correlation between C-15 and the acetyl methyl signal at
$\delta_{\mathrm{H}} 2$ 2.16. Furthermore, the position of the OAc-15 group was corroborated by the NOESY correlations between $\mathrm{Bz}-2^{\prime}, 6^{\prime}$ and OAc-15.

The relative configuration of $\mathbf{1}$ was elucidated as follows. For the reported natural myrsinol diterpenes, the three rings $(5 / 7 / 6)$ forming the myrsinol skeleton are trans-fused, $\mathrm{H}-4$ and $\mathrm{H}_{2}-17$ are $\alpha$-oriented, and Me-16, H-12, the side chain at C-11, and the C15 acetyl group are $\beta$-oriented (Figure 2). ${ }^{27} \mathrm{NOESY}$ correlations of 1 observed for H-2/H-3, H-3/H-4, H-4/H-14, H-4/H-2, and $\mathrm{H}-14 / \mathrm{H}-1 \mathrm{~b}$ suggested that $\mathrm{H}-1 \mathrm{~b}, \mathrm{H}-2, \mathrm{H}-3, \mathrm{H}-4$, and $\mathrm{H}-14$ are $\alpha$ oriented, while correlations between $\mathrm{H}-1 \mathrm{a} / \mathrm{H}_{3}-16$ and $\mathrm{H}-5 / \mathrm{H}-12$ proved the $\beta$-orientation of $\mathrm{H}-1 \mathrm{a}$ and $\mathrm{H}-5$.

This stereochemistry of $\mathbf{1}$ was in agreement with the configuration of 10,18-dihydromyrsinol diterpenes reported earlier. $^{28,29}$ All of the above evidence confirmed the structure of 1 as $5 \alpha, 10,14 \beta, 15 \beta$-O-tetraacetyl-3 $\beta$-O-benzoyl-10,18-dihydromyrsinol, which was named falcatin $\mathrm{A}$.

Compound 2 was obtained as an amorphous solid with $[\alpha]_{D}^{28}$ $+22\left(c 0.1, \mathrm{CHCl}_{3}\right)$. It was found to possess a molecular formula 
Table 2. ${ }^{13} \mathrm{C}$ NMR Data $\left(\delta_{\mathrm{C}}\right)$ of Compounds $1-6\left(\mathrm{CDCl}_{3}, 125 \mathrm{MHz}\right)$

\begin{tabular}{|c|c|c|c|c|c|c|}
\hline position & 1 & 2 & 3 & 4 & 5 & 6 \\
\hline 1 & 44.3, $\mathrm{CH}_{2}$ & 43.8, $\mathrm{CH}_{2}$ & 44.0, $\mathrm{CH}_{2}$ & $42.8, \mathrm{CH}_{2}$ & n.d. ${ }^{a}$ & 46.3, $\mathrm{CH}_{2}$ \\
\hline 2 & $36.5, \mathrm{CH}$ & $35.9, \mathrm{CH}$ & 36.1, CH & 36.0, CH & n.d. ${ }^{a}$ & $36.0, \mathrm{CH}$ \\
\hline 3 & 76.7, CH & 76.0, CH & 75.8, CH & 77.2, CH & $77.0, \mathrm{CH}$ & 78.4, $\mathrm{CH}$ \\
\hline 4 & $52.4, \mathrm{CH}$ & $52.4, \mathrm{CH}$ & $52.2, \mathrm{CH}$ & $50.9, \mathrm{CH}$ & $51.4, \mathrm{CH}$ & $50.1, \mathrm{CH}$ \\
\hline 5 & $66.8, \mathrm{CH}$ & $67.0, \mathrm{CH}$ & $66.8, \mathrm{CH}$ & $68.8, \mathrm{CH}$ & 69.1, CH & $69.0, \mathrm{CH}$ \\
\hline 6 & $61.8, \mathrm{C}$ & $61.7, \mathrm{C}$ & 61.7, C & $47.0, \mathrm{C}$ & n.d. ${ }^{a}$ & 47.1, C \\
\hline 7 & 197.3, C & 197.3, C & 197.3, C & $68.2, \mathrm{CH}$ & 68.0, CH & $68.3, \mathrm{CH}$ \\
\hline 8 & 131.6, CH & 131.7, CH & 131.6, CH & 126.1, CH & 126.3, CH & 126.3, CH \\
\hline 9 & $140.7, \mathrm{CH}$ & $140.8, \mathrm{CH}$ & $140.7, \mathrm{CH}$ & $129.0, \mathrm{CH}$ & $128.9, \mathrm{CH}$ & $128.9, \mathrm{CH}$ \\
\hline 10 & 85.4, C & $85.5, \mathrm{C}$ & 85.3, C & 79.3, C & $80.8, \mathrm{C}$ & 79.2, C \\
\hline 11 & $42.5, \mathrm{CH}$ & n.d. ${ }^{a}$ & n.d. ${ }^{a}$ & 47.4, $\mathrm{CH}$ & 47.7, $\mathrm{CH}$ & 47.6, CH \\
\hline 12 & $41.7, \mathrm{CH}$ & $41.5, \mathrm{CH}$ & $41.5, \mathrm{CH}$ & $41.8, \mathrm{CH}$ & 42.1, CH & $41.7, \mathrm{CH}$ \\
\hline 13 & 89.3, C & $89.2, \mathrm{C}$ & 89.3, C & $84.6, \mathrm{C}$ & $85.5, \mathrm{C}$ & $85.3, \mathrm{C}$ \\
\hline 14 & 81.1, CH & $81.0, \mathrm{CH}$ & $81.0, \mathrm{CH}$ & 200.2, C & 201.5, C & 205.3, C \\
\hline 15 & $90.4, \mathrm{C}$ & $90.5, \mathrm{C}$ & 90.3, C & $88.9, \mathrm{C}$ & $90.4, \mathrm{C}$ & 83.6, C \\
\hline 16 & $14.2, \mathrm{CH}_{3}$ & $14.2, \mathrm{CH}_{3}$ & 14.0, $\mathrm{CH}_{3}$ & $14.3, \mathrm{CH}_{3}$ & $14.5, \mathrm{CH}_{3}$ & $14.5, \mathrm{CH}_{3}$ \\
\hline 17 & $72.2, \mathrm{CH}_{2}$ & 72.2, $\mathrm{CH}_{2}$ & 72.1, $\mathrm{CH}_{2}$ & 61.4, $\mathrm{CH}_{2}$ & 61.3, $\mathrm{CH}_{2}$ & 61.6, $\mathrm{CH}_{2}$ \\
\hline 18 & 23.6, $\mathrm{CH}_{3}$ & 23.8, $\mathrm{CH}_{3}$ & 23.7, $\mathrm{CH}_{3}$ & $24.8, \mathrm{CH}_{3}$ & 25.0, $\mathrm{CH}_{3}$ & 24.6, $\mathrm{CH}_{3}$ \\
\hline 19 & $24.0, \mathrm{CH}_{3}$ & 24.0, $\mathrm{CH}_{3}$ & 23.9, $\mathrm{CH}_{3}$ & 29.7, $\mathrm{CH}_{3}$ & 29.4, $\mathrm{CH}_{3}$ & $29.5, \mathrm{CH}_{3}$ \\
\hline 20 & 23.6, $\mathrm{CH}_{3}$ & 23.0, $\mathrm{CH}_{3}$ & 23.5, $\mathrm{CH}_{3}$ & 26.1, $\mathrm{CH}_{3}$ & 26.0, $\mathrm{CH}_{3}$ & 24.7, $\mathrm{CH}_{3}$ \\
\hline OiBu-3 1 & & & 176.6, C & & & 175.2, C \\
\hline 2 & & & $34.3, \mathrm{CH}$ & & & $34.1, \mathrm{CH}$ \\
\hline 3 & & & 19.3, $\mathrm{CH}_{3}$ & & & 19.3, $\mathrm{CH}_{3}$ \\
\hline 4 & & & 19.3, $\mathrm{CH}_{3}$ & & & $19.0, \mathrm{CH}_{3}$ \\
\hline OAc-5 & 169.2, C & $169.4, \mathrm{C}$ & 169.4, C & & & \\
\hline & 21.1, $\mathrm{CH}_{3}$ & 21.2, $\mathrm{CH}_{3}$ & 21.2, $\mathrm{CH}_{3}$ & & & \\
\hline OAc-7 & & & & 170.0, C & 171.4, C & 170.0, C \\
\hline & & & & $21.2, \mathrm{CH}_{3}$ & $21.5, \mathrm{CH}_{3}$ & $21.2, \mathrm{CH}_{3}$ \\
\hline OAc-10 & 170.5, C & $170.4, \mathrm{C}$ & 170.4, C & & & \\
\hline & $22.4, \mathrm{CH}_{3}$ & $22.5, \mathrm{CH}_{3}$ & 22.4, $\mathrm{CH}_{3}$ & & & \\
\hline OAc-14 & 170.1, C & 170.1, C & 170.1, C & & & \\
\hline & 21.0, $\mathrm{CH}_{3}$ & 21.0, $\mathrm{CH}_{3}$ & 21.0, $\mathrm{CH}_{3}$ & & & \\
\hline OAc-15 & $168.3, \mathrm{C}$ & 168.3, C & 168.3, C & 168.0, C & 170.1, C & \\
\hline & 23.2, $\mathrm{CH}_{3}$ & 23.0, $\mathrm{CH}_{3}$ & 22.9, $\mathrm{CH}_{3}$ & 21.4, $\mathrm{CH}_{3}$ & 20.6, $\mathrm{CH}_{3}$ & \\
\hline OAc-17 & & & & & 171.9, C & \\
\hline & & & & & $21.5, \mathrm{CH}_{3}$ & \\
\hline $\mathrm{OBz} \mathrm{CO}$ & $166.8, \mathrm{C}$ & & & 165.5, C & 166.6, C & 165.0, C \\
\hline 1 & 131.0, C & & & 129.7, C & 130.7, C & 129.7, C \\
\hline 2,6 & $129.3, \mathrm{CH}$ & & & $129.6, \mathrm{CH}$ & $129.8, \mathrm{CH}$ & 129.6, CH \\
\hline 3,5 & $128.0, \mathrm{CH}$ & & & $128.3, \mathrm{CH}$ & $128.5, \mathrm{CH}$ & $128.3, \mathrm{CH}$ \\
\hline 4 & 132.6, CH & & & 133.3, CH & $133.3, \mathrm{CH}$ & 133.2, $\mathrm{CH}$ \\
\hline $\mathrm{O} i \mathrm{Bu}-31$ & & & & & 177.2, C & \\
\hline 2 & & & & & $35.6, \mathrm{CH}$ & \\
\hline 3 & & & & & 20.7, $\mathrm{CH}_{3}$ & \\
\hline 4 & & & & & $19.5, \mathrm{CH}_{3}$ & \\
\hline $\mathrm{OiBu}-171$ & & & & 176.5, C & & 176.5, C \\
\hline 2 & & & & $33.9, \mathrm{CH}$ & & $33.8, \mathrm{CH}$ \\
\hline 3 & & & & $19.0, \mathrm{CH}_{3}$ & & $19.0, \mathrm{CH}_{3}$ \\
\hline 4 & & & & 18.2, $\mathrm{CH}_{3}$ & & 17.6, $\mathrm{CH}_{3}$ \\
\hline OProp-3 1 & & $174.8, \mathrm{C}$ & & 173.1, C & & \\
\hline 2 & & 27.7, $\mathrm{CH}_{2}$ & & 27.4, $\mathrm{CH}_{2}$ & & \\
\hline 3 & & 9.0, $\mathrm{CH}_{3}$ & & 8.7, $\mathrm{CH}_{3}$ & & \\
\hline
\end{tabular}

of $\mathrm{C}_{31} \mathrm{H}_{42} \mathrm{O}_{12}$ based on the HRESIMS $\left[m / z 629.2600[\mathrm{M}+\mathrm{Na}]^{+}\right.$ (calcd for $\left.\mathrm{C}_{31} \mathrm{H}_{42} \mathrm{O}_{12} \mathrm{Na}, 629.2574\right)$ ). The ${ }^{1} \mathrm{H}$ NMR and JMOD spectra of 2 revealed four acetate $\left[\delta_{\mathrm{H}} 2.02 \mathrm{~s}, 2.03 \mathrm{~s}, 2.06\right.$ and 2.10 s; $\delta_{\mathrm{C}} 170.4,169.4,170.1$, and $168.3(\mathrm{CO})$ and $22.5,21.2,21.0$, and $\left.23.0\left(\mathrm{CH}_{3}\right)\right]$ and one propanoate $\left[\delta_{\mathrm{H}} 2.43 \mathrm{dq}, 2.31 \mathrm{dq}\right.$ and $1.16 \mathrm{t} ; \delta_{\mathrm{C}} 174.8,27.7$, and 9.0] group (Tables 1 and 2).
Additionally, the spectra exhibited resonances closely related to those of 1 .

After the ${ }^{1} \mathrm{H}$ and ${ }^{13} \mathrm{C}$ NMR data on 2 had been assigned by analysis of its ${ }^{1} \mathrm{H}-{ }^{1} \mathrm{H}$ COSY, HSQC, and HMBC spectra, it was obvious that compounds $\mathbf{1}$ and $\mathbf{2}$ are based on the same parent system and differ only in the substitution on C-3. The absence of 


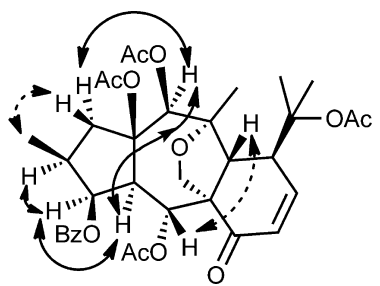

Figure 2. Diagnostic NOESY correlations of $\mathbf{1}$. signals for a benzoate group and the appearance of signals of a propanoate group indicated the replacement of a benzoate residue with a propanoate group. The position of the propanoyl group at $\mathrm{C}-3$ was corroborated by the HMBC cross-peak between $\delta_{\mathrm{H}} 5.41(\mathrm{H}-3)$ and the carbon signal at $\delta_{\mathrm{C}} 174.8$ (propanoyl CO). In the case of the acetyl groups, weak ${ }^{4} J_{\mathrm{C}, \mathrm{H}}$ couplings were also detected in the $\mathrm{HMBC}$ spectrum between $\mathrm{C}$ 5, C-10, and C-14 and the corresponding acetate methyl protons, proving unequivocally the locations of acetate groups.

\section{Table 3. ${ }^{1} \mathrm{H}$ NMR Data $\left(\delta_{\mathrm{H}}\right)$ of Compounds $7-12\left(\mathrm{CDCl}_{3}, 500 \mathrm{MHz}^{\mathrm{a}}\right.$ or $\left.600 \mathrm{MHz}^{\mathrm{b}}\right)$}

\begin{tabular}{|c|c|c|c|c|c|c|}
\hline position & $7^{\mathrm{b}}$ & $8^{a}$ & $9^{a}$ & $10^{\mathrm{a}}$ & $11^{\mathrm{a}}$ & $12^{\mathrm{a}}$ \\
\hline $1 \alpha$ & $2.89, \mathrm{dd}(15.5,11.5)$ & $2.55, \mathrm{~m}$ & $2.93, \mathrm{dd}(15.9,11.0)$ & $3.69, \mathrm{~d}(16.3)$ & $3.67, \mathrm{~d}(16.3)$ & $2.84, \mathrm{~d}(16.7)$ \\
\hline $1 \beta$ & $2.29, \mathrm{~m}$ & $2.78, \mathrm{~m}$ & $2.66, \mathrm{~m}$ & $1.97, \mathrm{~d}(16.3)$ & $2.00, \mathrm{~d}(16.2)$ & $3.83, \mathrm{~d}(16.8)$ \\
\hline 2 & $2.22, \mathrm{~m}$ & $2.20, \mathrm{~m}$ & $2.33, \mathrm{~m}$ & & & \\
\hline 3 & $5.68, \mathrm{t}(3.0)$ & $5.44, \mathrm{t}(3.9)$ & $5.73, \mathrm{t}(3.7)$ & $5.02, \mathrm{~d}(6.2)$ & $5.02, \mathrm{~d}(6.2)$ & $5.61, \mathrm{~d}(4.3)$ \\
\hline 4 & 3.16 , dd $(11.0,3.0)$ & 2.97, dd $(11.0,3.9)$ & 3.10 , dd $(10.6,3.6)$ & 2.94 , dd $(10.5,6.2)$ & $2.98, \mathrm{dd}(10.8,6.2)$ & $3.20, \mathrm{dd}(10.9,4.4)$ \\
\hline 5 & $6.13, \mathrm{~d}(11.0)$ & $5.90, \mathrm{~d}(11.0)$ & $5.86, \mathrm{~d}(10.6)$ & $5.93, \mathrm{~d}(10.5)$ & $5.93, \mathrm{~d}(10.8)$ & 5.91, d (10.7) \\
\hline 8 & $5.00, \mathrm{~d}(7.2)$ & $5.25, \mathrm{~d}(6.9)$ & $5.21, \mathrm{~d}(7.0)$ & $5.29, \mathrm{~d}(6.6)$ & $5.29, \mathrm{~d}(6.7)$ & $5.27, \mathrm{~d}(6.9)$ \\
\hline 9 & $2.81, \mathrm{~m}$ & $2.75, \mathrm{~m}$ & $2.73, \mathrm{~m}$ & $2.75, \mathrm{~m}$ & $2.70, \mathrm{~m}$ & $2.75, \mathrm{~m}$ \\
\hline 11 & $2.36, \mathrm{~m}$ & $2.41, \mathrm{dt}(12.5,2.0)$ & $2.40, \mathrm{~m}$ & $2.45, \mathrm{~m}$ & $2.50, \mathrm{dd}(10.5,7.4)$ & $2.48, \mathrm{~m}$ \\
\hline 12 & $3.99, \mathrm{~d}(12.6)$ & $4.09, \mathrm{~d}(12.5)$ & $4.10, \mathrm{~d}(12.3)$ & $3.96, \mathrm{~d}(12.2)$ & $3.96, \mathrm{~d}(12.3)$ & $4.01, \mathrm{~d}(12.3)$ \\
\hline 14 & $5.05, \mathrm{~s}$ & $5.04, \mathrm{~s}$ & $5.12, \mathrm{~s}$ & 4.94, s & $4.95, \mathrm{~s}$ & $5.05, \mathrm{~s}$ \\
\hline 16 & $0.87, \mathrm{~d}(6.6)$ & $0.86, \mathrm{~d}(6.8)$ & $0.94, \mathrm{~d}(6.7)$ & $1.46, \mathrm{~s}$ & $1.46, \mathrm{~s}$ & $1.79, \mathrm{~s}$ \\
\hline \multirow[t]{2}{*}{17} & $4.29, \mathrm{~d}(9.6)$ & $4.21, \mathrm{~d}(9.8)$ & $4.26, \mathrm{~d}(9.8)$ & $4.24, \mathrm{~d}(9.8)$ & $4.24, \mathrm{~d}(9.8)$ & $4.27, \mathrm{~d}(9.9)$ \\
\hline & $3.61, \mathrm{~d}(9.6)$ & $3.60, \mathrm{~d}(9.8)$ & $3.61, \mathrm{~d}(9.8)$ & $3.59, \mathrm{~d}(9.8)$ & $3.60, \mathrm{~d}(9.8)$ & 3.62 , d (9.9) \\
\hline 18 & $1.57, \mathrm{~s}$ & $1.64, \mathrm{~s}$ & $1.64, \mathrm{~s}$ & $1.66, \mathrm{~s}$ & $1.64, \mathrm{~s}$ & $1.65, \mathrm{~s}$ \\
\hline 19 & $2.58, \mathrm{~m}$ & $2.53, \mathrm{~m}$ & $2.50, \mathrm{~m}$ & $2.52, \mathrm{~d}(9.2)$ & $2.52, \mathrm{~m}$ & $2.52, \mathrm{~d}(9.1)$ \\
\hline 20 & $1.14, \mathrm{~s}$ & $1.20, \mathrm{~s}$ & $1.22, \mathrm{~s}$ & $1.18, \mathrm{~s}$ & $1.26, \mathrm{~s}$ & $1.20, \mathrm{~s}$ \\
\hline \multicolumn{7}{|l|}{$\mathrm{O} i \mathrm{Bu}-3$} \\
\hline 2 & & 2.46 , sept (7.1) & & & 2.51 , sept $(7.0)$ & $2.42, \mathrm{~m}$ \\
\hline 3 & & $1.17, \mathrm{~d}(7.1)$ & & & $1.18, \mathrm{~d}(7.1)$ & $1.06, \mathrm{~d}(6.9)$ \\
\hline 4 & & $1.14, \mathrm{~d}(6.9)$ & & & $1.10, \mathrm{~d}(6.9)$ & $1.00, \mathrm{~d}(7.2)$ \\
\hline \multicolumn{7}{|l|}{ OProp-3 } \\
\hline 2 & & & & $2.28, \mathrm{q}(7.6)$ & & \\
\hline 3 & & & & $1.10, \mathrm{t}(7.6)$ & & \\
\hline OAc-3 & $2.01, \mathrm{~s}$ & & & & & \\
\hline OAc-5 & & $1.92, \mathrm{~s}$ & $1.95, \mathrm{~s}$ & $1.90, \mathrm{~s}$ & $1.89, \mathrm{~s}$ & $1.96, \mathrm{~s}$ \\
\hline OAc-8 & & $2.27, \mathrm{~s}$ & & & & \\
\hline OAc-10 & $1.92, \mathrm{~s}$ & $2.10, \mathrm{~s}$ & $2.11, \mathrm{~s}^{c}$ & $2.09, \mathrm{~s}$ & $2.09, \mathrm{~s}$ & $2.08, \mathrm{~s}$ \\
\hline OAc-14 & $2.02, \mathrm{~s}$ & $2.10, \mathrm{~s}$ & $2.13, \mathrm{~s}$ & $2.09, \mathrm{~s}$ & $2.09, \mathrm{~s}$ & $2.11, \mathrm{~s}$ \\
\hline OAc-15 & $1.53, \mathrm{~s}$ & $2.20, \mathrm{~s}$ & $2.30, \mathrm{~s}^{c}$ & $2.18, \mathrm{~s}$ & $2.19, \mathrm{~s}$ & $2.16, \mathrm{~s}$ \\
\hline \multicolumn{7}{|l|}{ OBz-5 } \\
\hline 2,6 & $7.88, \mathrm{~d}(6.6)$ & & & & & \\
\hline 3,5 & $6.46, \mathrm{t}(7.8)$ & & & & & \\
\hline 4 & $7.12, \mathrm{t}(7.8)$ & & & & & \\
\hline \multicolumn{7}{|l|}{ OMeBu-8 } \\
\hline 2 & & & $2.20, \mathrm{~m}$ & $2.67, \mathrm{~m}$ & $2.65, \mathrm{~m}$ & $2.62 \mathrm{~m}$ \\
\hline 3 & & & $1.55, \mathrm{~m} ; 1.40, \mathrm{~m}$ & $1.75, \mathrm{~m} ; 1.60, \mathrm{~m}$ & $1.75, \mathrm{~m} ; 1.58, \mathrm{~m}$ & $1.63, \mathrm{~m} ; 1.72, \mathrm{~m}$ \\
\hline 4 & & & $0.78, \mathrm{t}(7.4)$ & $0.92, \mathrm{t}(7.5)$ & $0.92, \mathrm{t}(7.5)$ & $0.87, \mathrm{t}(7.4)$ \\
\hline 5 & & & $0.60, \mathrm{~d}(6.8)$ & $1.31, \mathrm{~d}(6.9)$ & $1.32, \mathrm{~d}(6.9)$ & $1.25, \mathrm{~d}(6.9)$ \\
\hline \multicolumn{7}{|l|}{ ONic } \\
\hline 2 & & & $9.10, \mathrm{~s}$ & & & $9.06, \mathrm{~s}$ \\
\hline 4 & & & $8.29, \mathrm{~d}(8.0)$ & & & $8.14, \mathrm{~d}(8.0)$ \\
\hline 5 & & & $7.40, \mathrm{dd}(7.8,4.8)$ & & & $7.35, \mathrm{dd}(7.8,4.9)$ \\
\hline 6 & & & $8.78, \mathrm{~d}(4.8)$ & & & $8.75, \mathrm{~d}(4.9)$ \\
\hline \multicolumn{7}{|l|}{ OBz-8 } \\
\hline 2,6 & $7.88, \mathrm{~d}(6.6)$ & & & & & \\
\hline 3,5 & $7.43, \mathrm{t}(7.2)$ & & & & & \\
\hline 4 & $7.62, \mathrm{t}(7.2)$ & & & & & \\
\hline
\end{tabular}

${ }^{c}$ Data are interchangeable. 
Table 4. ${ }^{13} \mathrm{C}$ NMR Data $\left(\delta_{\mathrm{C}}\right)$ of Compounds $7-12\left(\mathrm{CDCl}_{3}, 125 \mathrm{MHz}^{\mathrm{a}}\right.$ or $\left.150 \mathrm{MHz}^{\mathrm{b}}\right)$

\begin{tabular}{|c|c|c|c|c|c|c|}
\hline position & $7^{\mathrm{b}}$ & $8^{\mathrm{a}}$ & $9^{a}$ & $10^{\mathrm{a}}$ & $11^{\mathrm{a}}$ & $12^{\mathrm{a}}$ \\
\hline 1 & 43.2, $\mathrm{CH}_{2}$ & 43.1, $\mathrm{CH}_{2}$ & 43.3, $\mathrm{CH}_{2}$ & 51.0, $\mathrm{CH}_{2}$ & 51.0, $\mathrm{CH}_{2}$ & 48.3, $\mathrm{CH}_{2}$ \\
\hline 2 & $37.2, \mathrm{CH}$ & $36.3, \mathrm{CH}$ & 36.4, CH & 75.3, C & 75.5, C & 85.0, C \\
\hline 3 & 78.0, $\mathrm{CH}$ & 76.7, CH & 78.4, CH & $80.1, \mathrm{CH}$ & $80.0, \mathrm{CH}$ & $78.2, \mathrm{CH}$ \\
\hline 4 & $51.4, \mathrm{CH}$ & $51.0, \mathrm{CH}$ & $51.5, \mathrm{CH}$ & 49.6, CH & 49.4, CH & 47.2, $\mathrm{CH}$ \\
\hline 5 & $68.3, \mathrm{CH}$ & $68.9, \mathrm{CH}$ & $68.5, \mathrm{CH}$ & 69.5, CH & 69.5, CH & $68.4, \mathrm{CH}$ \\
\hline 6 & $62.3, \mathrm{C}$ & $62.2, \mathrm{C}$ & 62.1, C & $62.3, \mathrm{C}$ & $62.3, \mathrm{C}$ & $62.5, \mathrm{C}$ \\
\hline 7 & 204.3, C & 204.4, C & 204.4, C & 204.7, C & 204.7, C & 204.2, C \\
\hline 8 & 74.3, CH & 71.4, $\mathrm{CH}$ & $70.8, \mathrm{CH}$ & 71.3, CH & 71.3, CH & 71.2, $\mathrm{CH}$ \\
\hline 9 & $30.7, \mathrm{CH}$ & $29.8, \mathrm{CH}$ & $30.0, \mathrm{CH}$ & $30.1, \mathrm{CH}$ & $30.1, \mathrm{CH}$ & $30.1, \mathrm{CH}$ \\
\hline 10 & 77.8, C & 77.5, C & $77.5, \mathrm{C}$ & $77.5, \mathrm{C}$ & 77.6, C & 77.6, C \\
\hline 11 & $42.0, \mathrm{CH}$ & $41.8, \mathrm{CH}$ & 41.9, CH & 41.5, CH & 41.6, CH & $41.8, \mathrm{CH}$ \\
\hline 12 & 41.1, CH & 41.4, $\mathrm{CH}$ & 41.3, CH & 41.3, CH & 41.3, CH & 41.5, $\mathrm{CH}$ \\
\hline 13 & 89.6, C & $89.3, \mathrm{C}$ & 89.4, C & 88.6, C & 88.7, C & 89.3, C \\
\hline 14 & $81.9, \mathrm{CH}$ & $81.9, \mathrm{CH}$ & 82.0, CH & $80.8, \mathrm{CH}$ & 81.0, CH & $81.9, \mathrm{CH}$ \\
\hline 15 & $89.9, \mathrm{C}$ & 90.3, C & $90.5, \mathrm{C}$ & 89.9, C & 89.9, C & 88.6, C \\
\hline 16 & 13.9, $\mathrm{CH}_{3}$ & 13.9, $\mathrm{CH}_{3}$ & 14.1, $\mathrm{CH}_{3}$ & 29.7, $\mathrm{CH}_{3}$ & 29.7, $\mathrm{CH}_{3}$ & $25.0, \mathrm{CH}_{3}$ \\
\hline 17 & 67.4, $\mathrm{CH}_{2}$ & 67.1, $\mathrm{CH}_{2}$ & 67.1, $\mathrm{CH}_{2}$ & 66.9, $\mathrm{CH}_{2}$ & 67.0, $\mathrm{CH}_{2}$ & 67.3, $\mathrm{CH}_{2}$ \\
\hline 18 & 24.0, $\mathrm{CH}_{3}$ & 24.4, $\mathrm{CH}_{3}$ & 24.4, $\mathrm{CH}_{3}$ & 24.6, $\mathrm{CH}_{3}$ & 24.6, $\mathrm{CH}_{3}$ & 24.6, $\mathrm{CH}_{3}$ \\
\hline 19 & 37.1, $\mathrm{CH}_{2}$ & 35.0, $\mathrm{CH}_{2}$ & $34.9, \mathrm{CH}_{2}$ & 35.0, $\mathrm{CH}_{2}$ & 35.0, $\mathrm{CH}_{2}$ & $35.3, \mathrm{CH}_{2}$ \\
\hline 20 & 21.7, $\mathrm{CH}_{3}$ & $22.2, \mathrm{CH}_{3}$ & 22.3, $\mathrm{CH}_{3}$ & 22.0, $\mathrm{CH}_{3}$ & 22.3, $\mathrm{CH}_{3}$ & 22.4, $\mathrm{CH}_{3}$ \\
\hline OAc-3 & $\begin{array}{l}\text { 169.9, C } \\
21.0, \mathrm{CH}_{3}\end{array}$ & & & & & \\
\hline OAc-5 & & 170.0, C & 169.2, C & $169.5, \mathrm{C}$ & 169.5, C & 169.7, C \\
\hline & & 20.7, $\mathrm{CH}_{3}$ & $20.8, \mathrm{CH}_{3}$ & 20.7, $\mathrm{CH}_{3}$ & 20.6, $\mathrm{CH}_{3}$ & $20.9, \mathrm{CH}_{3}$ \\
\hline OAc- 8 & & $\begin{array}{l}168.5, \mathrm{C} \\
21.3, \mathrm{CH}_{3}\end{array}$ & & & & \\
\hline OAc-10 & $168.9, \mathrm{C}$ & 169.0, C & 169.2, C & 168.7, C & 168.7, C & $168.8, \mathrm{C}$ \\
\hline & 21.7, $\mathrm{CH}_{3}$ & 21.3, $\mathrm{CH}_{3}$ & 21.3, $\mathrm{CH}_{3}$ & 21.3, $\mathrm{CH}_{3}$ & 21.3, $\mathrm{CH}_{3}$ & 21.3, $\mathrm{CH}_{3}$ \\
\hline OAc-14 & $170.7, \mathrm{C}$ & $170.6, \mathrm{C}$ & $170.6, \mathrm{C}$ & $170.2, \mathrm{C}$ & $170.2, \mathrm{C}$ & $170.3, \mathrm{C}$ \\
\hline & 21.3, $\mathrm{CH}_{3}$ & $21.7, \mathrm{CH}_{3}$ & 21.7, $\mathrm{CH}_{3}$ & 21.3, $\mathrm{CH}_{3}$ & 21.6, $\mathrm{CH}_{3}$ & 21.7, $\mathrm{CH}_{3}$ \\
\hline OAc-15 & $167.5, \mathrm{C}$ & $167.9, \mathrm{C}$ & 168.1, C & $169.2, \mathrm{C}$ & 169.1, C & $168.2, \mathrm{C}$ \\
\hline & $22.6 \mathrm{CH}_{3}$ & 23.5, $\mathrm{CH}_{3}$ & 23.4, $\mathrm{CH}_{3}$ & 23.2, $\mathrm{CH}_{3}$ & 23.2, $\mathrm{CH}_{3}$ & 23.2, $\mathrm{CH}_{3}$ \\
\hline OProp-3 1 & & & & 174.3, C & & \\
\hline 2 & & & & 27.1, $\mathrm{CH}_{2}$ & & \\
\hline 3 & & & & $8.9, \mathrm{CH}_{3}$ & & \\
\hline OiBu-3 1 & & 176.0, C & & & 177.1, C & $175.3, \mathrm{C}$ \\
\hline 2 & & $34.3, \mathrm{CH}$ & & & $33.9, \mathrm{CH}$ & $34.1, \mathrm{CH}$ \\
\hline 3 & & 18.6, $\mathrm{CH}_{3}$ & & & 19.6, $\mathrm{CH}_{3}$ & 18.4, $\mathrm{CH}_{3}$ \\
\hline 4 & & 19.4, $\mathrm{CH}_{3}$ & & & $18.2, \mathrm{CH}_{3}$ & $19.0, \mathrm{CH}_{3}$ \\
\hline OBz-5 CO & 166.0, C & & & & & \\
\hline 1 & 129.5, C & & & & & \\
\hline 2,6 & 129.6, CH & & & & & \\
\hline 3,5 & $128.1, \mathrm{CH}$ & & & & & \\
\hline 4 & $132.8, \mathrm{CH}$ & & & & & \\
\hline OMeBu-8 1 & & & 174.6, C & 174.5, C & 174.6, C & 174.6, C \\
\hline 2 & & & $40.9, \mathrm{CH}$ & 41.0, CH & 41.0, $\mathrm{CH}$ & 41.1, CH \\
\hline 3 & & & 26.9, $\mathrm{CH}_{2}$ & 27.0, $\mathrm{CH}_{2}$ & 27.0, $\mathrm{CH}_{2}$ & 27.0, $\mathrm{CH}_{2}$ \\
\hline 4 & & & 11.0, $\mathrm{CH}_{3}$ & 11.0, $\mathrm{CH}_{3}$ & 11.0, $\mathrm{CH}_{3}$ & $11.0, \mathrm{CH}_{3}$ \\
\hline 5 & & & $15.0, \mathrm{CH}_{3}$ & $15.9, \mathrm{CH}_{3}$ & $15.7, \mathrm{CH}_{3}$ & $15.9, \mathrm{CH}_{3}$ \\
\hline OBz-8 CO & 166.5, C & & & & & \\
\hline 1 & 130.6, C & & & & & \\
\hline 2,6 & $129.8, \mathrm{CH}$ & & & & & \\
\hline 3,5 & 128.9, CH & & & & & \\
\hline 4 & 133.0, CH & & & & & \\
\hline ONic CO & & & 164.5, C & & & n.d. ${ }^{c}$ \\
\hline 2 & & & $150.1, \mathrm{CH}$ & & & $150.9, \mathrm{CH}$ \\
\hline 3 & & & $126.2, \mathrm{CH}$ & & & $128.0, \mathrm{CH}$ \\
\hline 4 & & & 137.1, CH & & & 137.5, $\mathrm{CH}$ \\
\hline 5 & & & $123.5, \mathrm{CH}$ & & & $123.8, \mathrm{CH}$ \\
\hline 6 & & & $153.5, \mathrm{CH}$ & & & $153.5, \mathrm{CH}$ \\
\hline
\end{tabular}


Table 4. continued

$c^{c}$.d. not detected.

Evaluation of the NOESY spectrum of $\mathbf{2}$ led to the conclusion that its configuration is the same as that of $\mathbf{1}$. Diagnostic nuclear Overhauser effects were detected between $\mathrm{H}-4 / \mathrm{H}-3, \mathrm{H}-4 / \mathrm{H}-1 \mathrm{~b}$, $\mathrm{H}-4 / \mathrm{H}-2, \mathrm{H}-4 / \mathrm{H}-14, \mathrm{H}-4 / \mathrm{H}-17 \mathrm{a}, \mathrm{H}-3 / \mathrm{OAc}-5$, and H-11/H-18, which proved the $\alpha$-orientation of these protons. Moreover, the cross-peaks between $\mathrm{H}-5 / \mathrm{H}-12$ and $\mathrm{H}-12 / \mathrm{H}-20$ supported the $\beta$-orientation of $\mathrm{H}-5, \mathrm{H}-12$, and $\mathrm{H}-20$. The structure of falcatin $\mathrm{B}$ (2) was elucidated therefore as $5 \alpha, 10,14 \beta, 15 \beta$-O-tetraacetyl-3 $\beta$ O-propanoyl-10,18-dihydromyrsinol.

Compound 3 was isolated as a colorless, amorphous solid with $[\alpha]_{\mathrm{D}}^{28}+13\left(c\right.$ 0.1, $\left.\mathrm{CHCl}_{3}\right)$. Its HRESIMS displayed a pseudomolecular ion peak at $m / z 643.2756[\mathrm{M}+\mathrm{Na}]^{+}$, indicating a molecular composition of $\mathrm{C}_{32} \mathrm{H}_{44} \mathrm{O}_{12}$. The ${ }^{1} \mathrm{H}$ NMR and JMOD spectra of 3 revealed four acetate and one isobutanoate group (Tables 1 and 2). Additionally, the spectra exhibited resonances closely related to those of 1 and $2 .{ }^{1} \mathrm{H}$ and ${ }^{13} \mathrm{C}$ NMR assignments of 3 , determined by analysis of the ${ }^{1} \mathrm{H}-{ }^{1} \mathrm{H}$ COSY, HSQC, and HMBC spectra, clearly showed that compounds 1-3 are based on the same parent system and differ only in the substitution at C-3. In the case of 3 , an isobutanoate group can be found in this position, and its location was corroborated by the $\mathrm{HMBC}$ cross-peak between $\delta_{\mathrm{H}} 5.39(\mathrm{H}-3)$ and the carbon signal at $\delta_{\mathrm{C}} 176.6$ (isobutanoyl CO). Comparison of the NOESY spectra of $\mathbf{2}$ and $\mathbf{3}$ indicated the same configuration for 3 and 2 . Therefore, falcatin $\mathrm{C}$ (3) was elucidated as $5 \alpha, 10,14 \beta, 15 \beta$-O-tetraacetyl- $3 \beta$-O-isobutyryl10,18-dihydromyrsinol.

Compound 4 was obtained as an amorphous solid with $[\alpha]^{25}$ +16 (c $0.1, \mathrm{CHCl}_{3}$ ). It gave the molecular formula $\mathrm{C}_{38} \mathrm{H}_{48} \mathrm{O}_{12}$, as determined from the HRESIMS by the protonated molecular ion peak at $\mathrm{m} / z$ 697.3256 $[\mathrm{M}+\mathrm{H}]^{+}$(calcd for $\mathrm{C}_{38} \mathrm{H}_{49} \mathrm{O}_{12}$, 697.3224). Apart from the signals for the benzoyl group, the main difference between 4 and 3 was the transposition of the locations of the keto group (at C-7 in 3 and C-14 in 4) and an ester group (at C-14 in 3 and C-7 in 4) (Tables 1 and 2). In addition, the chemical shift values of C-10 $\left(\delta_{\mathrm{C}} 79.3\right)$ and $\mathrm{C}-13$ $\left(\delta_{\mathrm{C}} 84.6\right)$ suggested a rearranged tetrahydrofuran ring in the structure due to the ether bridge between $\mathrm{C}-10$ and $\mathrm{C}-13$ in 4. ${ }^{30-32}$ In compound 4, the $\mathrm{OH}-17$ group was esterified with an isobutanoic acid, as indicated by the HMBC cross-peaks between the carbon signal at $\delta_{\mathrm{C}} 176.5(i \mathrm{Bu} \mathrm{CO})$ and $\mathrm{H}-17$. The locations of the acyl groups at $\mathrm{C}-3, \mathrm{C}-5$, and $\mathrm{C}-7$ were determined by the HMBC correlations of $\mathrm{H}-3, \mathrm{H}-5$, and $\mathrm{H}-7$ to the corresponding carbonyl carbons of the acyl groups. The remaining acetoxy group was attached of necessity at C-15. The myrsinol-type diterpene skeleton of 4 implied the same trans-fusion of the three rings as those of compounds $1-3$. The NOESY correlations of $\mathrm{H}-2 / \mathrm{H}-3, \mathrm{H}-3 / \mathrm{H}-4$, and $\mathrm{H}-4 / \mathrm{H}_{2}-17$ suggested that $\mathrm{H}-3, \mathrm{H}-4$, and $\mathrm{H}-17$ are $\alpha$-oriented. Correlations of $\mathrm{H}-5 / \mathrm{H}-12$ and $\mathrm{H}-12 /$ $\mathrm{H}_{3}-18$ proved the $\beta$-orientation of $\mathrm{H}-5, \mathrm{H}-12$, and $\mathrm{H}_{3}-18$, while NOEs between $\mathrm{H}-19 / \mathrm{H}-11$ and $\mathrm{H}-20 / \mathrm{H}-17 / \mathrm{H}-1 \mathrm{a} / \mathrm{H}-4$ confirmed the $\alpha$-orientation of these protons. Thus, compound 4 (falcatin D) was elucidated as $7 \beta, 15 \beta$-O-diacetyl-5 $\alpha$-O-benzoyl$17 \alpha$-O-isobutanoyl-3 $\beta$-O-propanoyl-10,13-epoxy-10,18-dihydromyrsinol.

The molecular formula for compound $\mathbf{5}$ was determined as $\mathrm{C}_{37} \mathrm{H}_{46} \mathrm{O}_{12}$ on the basis of the HRESIMS $[\mathrm{m} / z$ 683.3092 $[\mathrm{M}+$ $\mathrm{H}]^{+}$(calcd for $\left.\mathrm{C}_{37} \mathrm{H}_{47} \mathrm{O}_{12}, 683.3068\right)$. Comparing the chemical shifts for the skeletal carbons in 5 with those of compound 4 , the close similarity implied that compounds $\mathbf{4}$ and $\mathbf{5}$ possess the same 10,13-epoxy-10,18-dihydromyrsinol framework (Tables 1 and 2). Following the same NMR procedures used for 4 , the locations of the acyloxy groups in $\mathbf{5}$ and the configuration of the compound were determined by analysis of the HMBC and NOESY spectra. $\mathrm{HMBC}$ cross-peaks revealed acetoxy groups at C-7, C-15, and C17 , the isobutyryloxy group at $\mathrm{C}-3$, and the benzoyloxy group at $\mathrm{C}-5$, respectively. NOESY correlations of $\mathrm{H}-2 / \mathrm{H}-3, \mathrm{H}-3 / \mathrm{H}-4, \mathrm{H}-$ 4/H $\mathrm{H}_{2}-17, \mathrm{H}_{2}-17 / \mathrm{H}-7, \mathrm{H}-5 / \mathrm{H}-12, \mathrm{H}-12 / \mathrm{H}_{3}-18, \mathrm{H}-11 / \mathrm{H}_{3}-19$, and $\mathrm{H}_{2}-17 / \mathrm{H}_{3}-20$ allowed the stereochemical features to be assigned, which were identical with those of compound 4 . The structure of falcatin $\mathrm{E}$ was elucidated therefore as $7 \beta, 15 \beta, 17 \alpha$-O-triacetyl- $5 \alpha$ $O$-benzoyl-3 $\beta$-O-isobutyryl-10,13-epoxy-10,18-dihydromyrsinol.

Compound 6 was obtained as an amorphous solid with $[\alpha]^{25}$ $+2\left(c 0.1, \mathrm{CHCl}_{3}\right)$. It exhibited a molecular formula of $\mathrm{C}_{37} \mathrm{H}_{48} \mathrm{O}_{11}$ based on the HRESIMS $\left[\mathrm{m} / z 691.3125[\mathrm{M}+\mathrm{Na}]^{+}\right.$(calcd for $\left.\left.\mathrm{C}_{37} \mathrm{H}_{48} \mathrm{O}_{11} \mathrm{Na}, 691.3094\right)\right]$. The ${ }^{1} \mathrm{H}$ and ${ }^{13} \mathrm{C}$ NMR spectra of compound $\mathbf{6}$ were similar to those of $\mathbf{4}$ and $\mathbf{5}$ (Tables 1 and 2). For compound 6, one acetoxy group, two isobutyryloxy units, and one benzoyloxy group were evident from its 1D NMR spectra (Table 1). The position of the acyloxy groups and the configuration of 6 were determined using HMBC and NOESY experiments. Nuclear Overhauser effects indicated that $\mathrm{H}-2, \mathrm{H}-3$, $\mathrm{H}-4, \mathrm{H}-7, \mathrm{H}_{2}-17$, and $\mathrm{H}_{3}-20$ are $\alpha$-oriented and $\mathrm{H}-5, \mathrm{H}-12$, and the epoxy bridge are $\beta$-oriented. The differences between $\mathbf{6}$ and $\mathbf{5}$ were the presence of an isobutyroyl group at C-17 and a hydroxy group at $\mathrm{C}-15$ instead of two acetyl groups at these positions. Therefore, compound 6 (falcatin $\mathrm{F}$ ) was elucidated as $7 \beta$-Oacetyl-5 $\alpha$-O-benzoyl-15 $\beta$-hydroxy-3 $\beta, 17-O$-diisobutyryl-10,13epoxy-10,18-dihydromyrsinol.

The molecular formula $\mathrm{C}_{40} \mathrm{H}_{44} \mathrm{O}_{13}$ of falcatin $\mathrm{G}$ (7) was assigned according to the HRESIMS at $m / z 775.2986[\mathrm{M}+\mathrm{H}]^{+}$ (calcd for $\mathrm{C}_{42} \mathrm{H}_{47} \mathrm{O}_{14}, 775.2966$ ). From the ${ }^{1} \mathrm{H}$ and ${ }^{13} \mathrm{C}$ NMR spectra, three acetoxy and two benzoyloxy groups were evident (Tables 3 and 4). The remaining 20 resonances in the ${ }^{13} \mathrm{C}$ NMR spectrum suggested a cyclomyrsinol-type diterpene skeleton for 7. The characteristic cyclobutane ring, which is built with incorporation of one of the geminal dimethyl groups (C-19) besides C-9, C-10, and C-11 of the myrsinane skeleton, can be characterized by two methines $\left[\delta_{\mathrm{C}} 29.8-30.7\right.$ (C-9), 41.1-41.5 $(\mathrm{C}-11)]$, one methylene $\left[\delta_{\mathrm{C}} 34.6-37.1(\mathrm{C}-19)\right]$, and one Osubstituted quaternary carbon $\left[\delta_{\mathrm{C}} 77.5-77.8(\mathrm{C}-10)\right]$, due to the connection of an ester and a methyl group (C-18) in this position. $^{25,28,29}$

The substitution pattern of compound 7 was determined using $\mathrm{HMBC}$ and NOESY experiments. The HMBC correlations of $\mathrm{H}$ $3, \mathrm{H}-5, \mathrm{H}-8$, and $\mathrm{H}-14$ to the corresponding carbonyl carbons revealed that the two acetoxy and two benzoyloxy groups are attached at C-3, C-5 and C-8, C-14, respectively. The remaining acetoxy groups were placed at $\mathrm{C}-10$ and $\mathrm{C}-15$. NOESY correlations observed for H-2/H-3, H-3/H-4, H-4/H-14, H-8/ $\mathrm{H}-9, \mathrm{H}-9 / \mathrm{H}_{3}-18, \mathrm{H}-11 / \mathrm{H}-18, \mathrm{H}-11 / \mathrm{H}-17$, and $\mathrm{H}-5 / \mathrm{H}-12$ suggested that the $\mathrm{H}-3, \mathrm{H}-8, \mathrm{H}-11, \mathrm{H}-14, \mathrm{H}-17$, and $\mathrm{H}_{3}-18$ are $\alpha$-oriented and $\mathrm{H}-5$ and $\mathrm{H}-12$ are $\beta$-oriented. These assignments were consistent with the configurations of reported cyclomyrsinol diterpenes. $^{25,28,29}$ Therefore, compound 7 (falcatin G) was identified as $3 \beta, 10 \beta, 14 \beta, 15 \beta$-O-tetraacetyl-5 $\alpha, 8 \alpha$-O-dibenzoylcyclomyrsinol. 
The ${ }^{1} \mathrm{H}$ and ${ }^{13} \mathrm{C}$ NMR spectra of compounds 8 and 9 were similar to those of falcatin G (7) (Tables 3 and 4). Chemical shift values for the 20 skeletal carbons were close to those of $3,5,8,10,14,15-O$-hexaacylcyclomyrsinol, which implied that these compounds are polyesters of the same parent alcohol. For compound $\mathbf{8}$, five acetoxy and one isobutyryloxy group were evident from its ${ }^{13} \mathrm{C}$ and ${ }^{1} \mathrm{H}$ NMR spectra. HMBC and NOESY experiments allowed the determination of the positions of the acyloxy groups and the relative configuration of $\mathbf{8}$ (Figure 3).

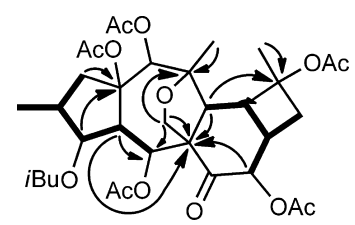

Figure 3. Selected ${ }^{1} \mathrm{H}-{ }^{1} \mathrm{H}$ COSY (bold) and $\operatorname{HMBC}(\mathrm{C} \rightarrow \mathrm{H})$ correlations for $\mathbf{8}$.

NOESY correlations demonstrated that $\mathrm{H}-2, \mathrm{H}-3, \mathrm{H}-4, \mathrm{H}-8$, $\mathrm{H}-9, \mathrm{H}-11, \mathrm{H}-14$, and $\mathrm{H}_{2}-17$ are $\alpha$-oriented and $\mathrm{H}-5, \mathrm{H}-12$, and $\mathrm{H}_{3}-20$ are $\beta$-oriented. The two differences between 9 and 8 were that the C-3 isobutyryl and C-8 benzoyl groups in 8 were replaced by nicotinyl (C-3) and 2-methylbutyryl (C-8) groups in 9. Therefore, compounds 8 and 9 were elucidated as $5 \alpha, 8 \beta, 10 \beta, 14 \beta, 15 \beta$-O-pentaacetyl-3 $\beta$-O-isobutyrylcyclomyrsinol $(8)$ and $5 \alpha, 10 \beta, 14 \beta, 15 \beta$-O-tetraacetyl-3 $\beta$-isobutyryl- $8 \beta$-O(2-methylbutyryl)-3 $\beta$-O-nicotinylcyclomyrsinol (9) and were named falcatins $\mathrm{H}$ and $\mathrm{I}$, respectively.

Analysis of the ${ }^{1} \mathrm{H}$ and ${ }^{13} \mathrm{C}$ NMR data (Tables 3-6) of compounds 10-15 revealed all compounds to be based on a cyclomyrsinane skeleton in a similar manner to 8 and 9 , but having a hydroxy or acyloxy group substituent at C-2, as indicated by the carbon signals at $\delta_{\mathrm{C}-2} 75.3-85.0 \mathrm{ppm}$. After defining the skeleton by ${ }^{1} \mathrm{H}-{ }^{1} \mathrm{H}$ COSY and HSQC measurements, HMBC and NOESY experiments were performed to determine the locations of the acyl groups and the configurations. For compound 10, four acetoxy groups at C-5, C-10, C-14, and C15 , a propionyloxy group at C-3, a 2-methylbutyryloxy group at $\mathrm{C}-8$, and a hydroxy group at $\mathrm{C}-2$ were elucidated. The only difference found between $\mathbf{1 1}$ and $\mathbf{1 0}$ was that the C-3 propionyloxy group in $\mathbf{1 0}$ was replaced by an isobutyryloxy group in 11. Compound $\mathbf{1 2}$ differs from $\mathbf{1 1}$ by the substitution at $\mathrm{C}-2$. In the case of $\mathbf{1 2}$, a nicotinyloxy group was determined as being present instead of a hydroxy group in 11, as indicated by the chemical shift values of C-2 (11: $75.5 \mathrm{ppm}, 12: 85.0 \mathrm{ppm}$ ).

The only structural difference between 12 and 13 was the presence of an isobutyryloxy group at C-8 in $\mathbf{1 3}$ instead of the 2methylbutyryloxy group in 12. Compound 14 differed from 13 also in that a propionyloxy group was determined at C-3 instead of the isobutyryloxy group found in $\mathbf{1 3}$. Compound $\mathbf{1 5}$ was a close analogue of 10, differing only in the substituent at C-2 (hydroxy in 10 and benzoyloxy in 15).

NOE effects observed between $\mathrm{H}-3 / \mathrm{H}-4, \mathrm{H}-4 / \mathrm{H}-14, \mathrm{H}-4 / \mathrm{H}_{3}-$ 16, H-4/H-17a, H-11/H-17b, H-14/H-1 $\alpha$, H-8/H-9, H-9/H-18, $\mathrm{H}-18 / \mathrm{H}-11$, and $\mathrm{H}-5 / \mathrm{H}-12$ in compounds $10-15$ revealed that these compounds have the same configuration, namely, $\mathrm{H}-3, \mathrm{H}-$ 4, $\mathrm{H}-9, \mathrm{H}-11, \mathrm{H}-14$, and $\mathrm{H}_{2}-17$ in an $\alpha$-orientation and $\mathrm{H}-5$ and $\mathrm{H}-12 \beta$-oriented. All of the above evidence confirmed the structures of these compounds as depicted in structural formulas 10-15, and the compounds were named falcatins $\mathrm{J}-\mathrm{O}$, respectively.

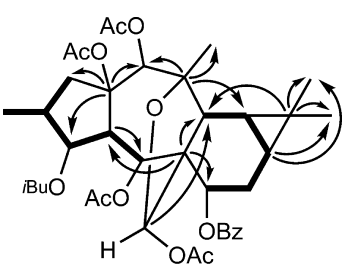

Figure 4. Selected ${ }^{1} \mathrm{H}-{ }^{1} \mathrm{H}$ COSY (bold) and $\operatorname{HMBC}(\mathrm{C} \rightarrow \mathrm{H})$ correlations for $\mathbf{1 6 .}$

The ${ }^{1} \mathrm{H}$ and ${ }^{13} \mathrm{C}$ NMR spectra of compounds $16-18$ were very similar (Tables 5-7). From the NMR spectra, a hemiacetal moiety between C-13 and C- 6 could be elucidated with regard to the oxymethine signals at $\delta_{\mathrm{H}} 6.36-6.49 \mathrm{~s}$ and $\delta_{\mathrm{C}} 97.1(17-\mathrm{CH})$. In the case of all three compounds, six acyl groups were identified. The ${ }^{1} \mathrm{H}$ NMR and ${ }^{1} \mathrm{H}-{ }^{1} \mathrm{H}$ COSY spectra revealed the structural elements $-\mathrm{CH}_{2}-\mathrm{CH}\left(\mathrm{CH}_{3}\right)-\mathrm{CHR}-\mathrm{CH}-\mathrm{CHR}-(\mathrm{C}-$ $1-\mathrm{C}-2(\mathrm{C}-16)-\mathrm{C}-3-\mathrm{C}-4-\mathrm{C}-5)$ and $-\mathrm{CHR}-\mathrm{CH}_{2}-\mathrm{CH}-\mathrm{CH}-$ $\mathrm{CH}-(\mathrm{C}-7-\mathrm{C}-12)$. The connection of these partial structural parts was carried out with the use of HMBC correlations. Diagnostic HMBC cross-peaks between C-17/H-5, C-17/H-7, C-17/H-12, C-10/H-18, C-10/H-19, C-10/H-12, C-9/H-18, C$9 / \mathrm{H}-19$, and $\mathrm{C}-9 / \mathrm{H}-11$ led to the conclusion that these compounds are premyrsinane derivatives. For compound 16, four acetoxy, one isobutyryloxy, and one benzoyloxy group were identified from its ${ }^{13} \mathrm{C}$ and ${ }^{1} \mathrm{H}$ NMR spectra. The locations of the ester groups were established from the HMBC spectra, with the acetoxy groups present at C-5, C-14, C-15, and C-17, an isobutyryloxy group at $\mathrm{C}-3$, and a benzoyloxy group at $\mathrm{C}-7$ (Figure 4).

In the case of 17 , in addition to acetyl substituents at C-5, C15 , and $\mathrm{C}-17$ and the isobutanoyl group at $\mathrm{C}-3$, a nicotinyl group and a benzoyl group were determined at C-8 and C-14, respectively. Compound 18 was found to possess a propionyloxy moiety at C-3 instead of the isobutyryloxy moiety in $\mathbf{1 7}$ (Tables 5-7). A careful comparison of the NOESY spectra of 16-18 indicated the same configuration for all three compounds. A strong NOESY cross-peak between $\mathrm{H}-4 / \mathrm{H}-17$ proved the $\alpha$ orientation of the $\mathrm{C}-17$ methine proton. Moreover, NOE correlations observed for $\mathrm{H}-2 / \mathrm{H}-3, \mathrm{H}-3 / \mathrm{H}-4, \mathrm{H}-4 / \mathrm{H}-14, \mathrm{H}-7 /$ $\mathrm{H}-8 \mathrm{a}, \mathrm{H}-8 \mathrm{a} / \mathrm{H}-9, \mathrm{H}-9 / \mathrm{H}-11, \mathrm{H}-5 / \mathrm{H}-12$, and $\mathrm{H}-12 / \mathrm{H}_{3}-20$ indicated that $\mathrm{H}-2, \mathrm{H}-3, \mathrm{H}-4, \mathrm{H}-7, \mathrm{H}-9, \mathrm{H}-11$, and $\mathrm{H}-14$ are $\alpha$ oriented, while $\mathrm{H}-5, \mathrm{H}-12$, and $\mathrm{H}_{3}-20$ are oriented in a $\beta$-manner. Therefore, compounds 16-18 (falcatins $\mathrm{P}-\mathrm{R}$ ) were elucidated as $5 \alpha, 14 \beta, 15 \beta, 17-O$-tetraacetyl-7 $\beta$-O-benzoyl-3 $\alpha$-O-isobutyrylpremyrsinol (16), $5 \alpha, 15 \beta, 17-O$-triacetyl-14 $\beta$-benzoyl- $3 \alpha$-O-isobutyryl-7 $\beta$-O-nicotinylpremyrsinol (17), and $5 \alpha, 15 \beta, 17-O$-triacetyl-14 $\beta$-benzoyl-7 $\beta$-O-nicotinyl-3 $\alpha$-O-propionylpremyrsinol (18), respectively.

The molecular formula, $\mathrm{C}_{41} \mathrm{H}_{49} \mathrm{NO}_{12}$, was determined for compound 19 by the HRESIMS at $m / z 748.3373[\mathrm{M}+\mathrm{H}]^{+}$ (calcd for $\mathrm{C}_{41} \mathrm{H}_{50} \mathrm{NO}_{12}, 748.3333$ ). Analysis of its ${ }^{13} \mathrm{C} \mathrm{NMR}$ spectrum (Table 6 ) revealed the presence of five ester carbonyls $\left(\delta_{\mathrm{C}} 164.7,164.9,170.0,170.6\right.$, and 176.0), which could be assigned to a nicotinate, a benzoate, two acetate, and one isobutanoate unit, respectively, based on diagnostic resonances in the ${ }^{1} \mathrm{H}$ and ${ }^{13} \mathrm{C}$ NMR spectra (Tables 6 and 7). Analysis of the ${ }^{1} \mathrm{H}-{ }^{1} \mathrm{H}$ COSY spectrum allowed the identification of the two spin systems, $-\mathrm{CH}_{2}-\mathrm{CH}\left(\mathrm{CH}_{3}\right)-\mathrm{CH}(\mathrm{R})-\mathrm{CH}-\mathrm{CH}(\mathrm{R})-(\mathrm{A})$ and $-\mathrm{CH}(\mathrm{R})-\mathrm{CH}_{2}-\mathrm{CH}-\mathrm{CH}-\mathrm{CH}-(\mathrm{B})$, and an isolated $\mathrm{O}$ substituted methylene $\left(-\mathrm{CH}_{2}-\mathrm{OR}\right)$. HMBC cross-peaks between C-6 and H-5, H-17a, H-12, H-4, and H-8, between C7 and $\mathrm{H}-5, \mathrm{H}-17$, and $\mathrm{H}-8$, and between $\mathrm{C}-10$ and $\mathrm{H}-7, \mathrm{H}-12, \mathrm{H}-$ 
Table 5. ${ }^{1} \mathrm{H}$ NMR Data $\left(\delta_{\mathrm{H}}\right)$ of Compounds 13-17 $\left(\mathrm{CDCl}_{3}, 500 \mathrm{MHz}^{a}\right.$ or $\left.600 \mathrm{MHz}^{b}\right)$

\begin{tabular}{|c|c|c|c|c|c|}
\hline position & $13^{a}$ & $14^{a}$ & $15^{a}$ & $16^{b}$ & $17^{a}$ \\
\hline $1 \alpha$ & $3.84, \mathrm{~d}(16.8)$ & $4.22, \mathrm{~d}(16.9)$ & $4.15, \mathrm{~d}(16.8)$ & $2.62, \mathrm{~m}$ & $2.78, \mathrm{dd}(16.1,10.2)$ \\
\hline $1 \beta$ & $2.84, \mathrm{~d}(16.7)$ & $2.42, \mathrm{~d}(16.7)$ & $2.44, \mathrm{~d}(16.7)$ & $2.39, \mathrm{~m}$ & $2.67, \mathrm{dd}(16.1,10.0)$ \\
\hline 2 & & & & $2.02, \mathrm{~m}$ & $2.15, \mathrm{~m}$ \\
\hline 3 & $5.61, \mathrm{~d}(4.4)$ & $5.57, \mathrm{~d}(5.5)$ & $5.60, \mathrm{~d}(5.4)$ & $5.02, \mathrm{t}(3.6)$ & $5.12, \mathrm{t}(3.8)$ \\
\hline 4 & 3.21 , dd $(10.8,4.4)$ & 3.08 , dd $(10.8,5.6)$ & 3.08 , dd $(10.8,5.4)$ & 3.02 , dd $(10.8,3.6)$ & 3.17 , dd $(10.7,3.7)$ \\
\hline 5 & $5.92, \mathrm{~d}(10.8)$ & $5.94, \mathrm{~d}(10.7)$ & $5.90, \mathrm{~d}(10.7)$ & $5.77, \mathrm{~d}(10.8)$ & $5.88, \mathrm{~d}(10.6)$ \\
\hline 7 & & & & 5.31 , dd $(10.8,3.1)$ & 5.42 , dd $(10.6,3.5)$ \\
\hline 8 & $5.27, \mathrm{~d}(6.6)$ & $5.28, \mathrm{~d}(6.6)$ & $5.27, \mathrm{~d}(6.6)$ & $2.02, \mathrm{~m} ; 1.55, \mathrm{~m}$ & $2.15, \mathrm{~m} ; 1.70 \mathrm{~m}$ \\
\hline 9 & $2.76, \mathrm{~m}$ & $2.76, \mathrm{~m}$ & $2.74, \mathrm{~m}$ & $0.91, \mathrm{~m}$ & $1.02, \mathrm{~m}$ \\
\hline 11 & $2.52, \mathrm{~m}$ & $2.47, \mathrm{~m}$ & $2.46, \mathrm{~m}$ & $0.74, \mathrm{~m}$ & $0.89, \mathrm{t}(7.0)$ \\
\hline 12 & $4.04, \mathrm{~d}(12.3)$ & $3.97, \mathrm{~d}(12.2)$ & $3.97, \mathrm{~d}(12.2)$ & $2.66, \mathrm{~m}$ & $2.93, \mathrm{~d}(7.0)$ \\
\hline 14 & $5.05, \mathrm{~s}$ & $5.03, \mathrm{~s}$ & $5.03, \mathrm{~s}$ & 4.97, s & $5.30, \mathrm{~s}$ \\
\hline 16 & $1.80, \mathrm{~s}$ & $1.83, \mathrm{~s}$ & $1.80, \mathrm{~s}$ & $0.69, \mathrm{~d}(6.6)$ & $0.76, \mathrm{~d}(6.8)$ \\
\hline \multirow[t]{2}{*}{17} & $4.27, \mathrm{~d}(9.8)$ & $4.26, \mathrm{~d}(9.8)$ & $4.27, \mathrm{~d}(9.8)$ & 6.36, s & $6.48, \mathrm{~s}$ \\
\hline & $3.64, \mathrm{~d}(9.8)$ & 3.62 , d (9.9) & $3.61, \mathrm{~d}(9.8)$ & & \\
\hline 18 & $1.66, \mathrm{~s}$ & $1.64, \mathrm{~s}$ & $1.64, \mathrm{~s}$ & $1.13, \mathrm{~s}$ & $1.28, \mathrm{~s}$ \\
\hline 19 & $2.52, \mathrm{~m}$ & $2.52, \mathrm{~m}$ & $2.52, \mathrm{~m}$ & $1.13, \mathrm{~s}$ & $1.18, \mathrm{~s}$ \\
\hline 20 & $1.22, \mathrm{~s}$ & $1.20, \mathrm{~s}$ & $1.20, \mathrm{~s}$ & $1.29, \mathrm{~s}$ & 1.37, s \\
\hline \multicolumn{6}{|l|}{ OProp-3 } \\
\hline 2 & & $2.21, \mathrm{~m}, 2.16, \mathrm{dq}(16.5,7.5)$ & $2.17, \mathrm{~m}$ & & \\
\hline 3 & & $1.06, \mathrm{t}(7.5)$ & $1.04, \mathrm{t}(7.5)$ & & \\
\hline \multicolumn{6}{|l|}{$\mathrm{OiBu}-3$} \\
\hline 2 & 2.40 , sept (7.0) & & & $2.43, \mathrm{~m}$ & 2.49, sept $(7.0)$ \\
\hline 3 & $1.06, \mathrm{~d}(6.9)$ & & & $1.07, \mathrm{~d}(6.6)$ & $1.11, \mathrm{~d}(7.0)$ \\
\hline 4 & $1.00, \mathrm{~d}(7.1)$ & & & $1.05, \mathrm{~d}(6.6)$ & $1.09, \mathrm{~d}(7.0)$ \\
\hline OAc-5 & $1.96, \mathrm{~s}$ & $1.94, \mathrm{~s}$ & $1.94, \mathrm{~s}$ & $1.23, \mathrm{~s}$ & $1.39, \mathrm{~s}$ \\
\hline OAc-10 & $2.10, \mathrm{~s}$ & $2.07, \mathrm{~s}$ & $2.08, \mathrm{~s}$ & & \\
\hline OAc-14 & $2.12, \mathrm{~s}$ & $2.09, \mathrm{~s}$ & $2.11, \mathrm{~s}$ & $1.98, \mathrm{~s}$ & \\
\hline OAc-15 & $2.16, \mathrm{~s}$ & $2.05, \mathrm{~s}$ & $2.05, \mathrm{~s}$ & $2.04, \mathrm{~s}$ & $2.08, \mathrm{~s}$ \\
\hline OAc-17 & & & & $2.13, \mathrm{~s}$ & $2.21, \mathrm{~s}$ \\
\hline \multicolumn{6}{|l|}{$\mathrm{OiBu}-8$} \\
\hline 2 & $2.76, \mathrm{~m}$ & $2.76, \mathrm{~m}$ & & & \\
\hline 3 & $1.26, \mathrm{~d}(6.8)$ & $1.24, \mathrm{~d}(7.0)$ & & & \\
\hline 4 & $1.23, \mathrm{~d}(7.2)$ & $1.28, \mathrm{~d}(6.8)$ & & & \\
\hline \multicolumn{6}{|l|}{ OMeBu-8 } \\
\hline 2 & & & $2.52, \mathrm{~m}$ & & \\
\hline 3 & & & $1.29, \mathrm{~d}(7.0)$ & & \\
\hline 4 & & & $0.88, \mathrm{t}(7.0)$ & & \\
\hline 5 & & & $1.23, \mathrm{~d}(7.1)$ & & \\
\hline \multicolumn{6}{|l|}{ ONic } \\
\hline 2 & $9.06, \mathrm{~s}$ & $9.03, \mathrm{~s}$ & & & $9.15, \mathrm{~s}$ \\
\hline 4 & $8.15, \mathrm{~d}(7.9)$ & $8.18, \mathrm{~d}(8.0)$ & & & $8.23, \mathrm{~d}(7.9)$ \\
\hline 5 & 7.36, dd $(8.0,5.0)$ & 7.39 , dd $(8.1,4.9)$ & & & 7.38 , dd $(7.8,4.9)$ \\
\hline 6 & $8.76, \mathrm{~d}(4.8)$ & $8.76, \mathrm{~d}(4.8)$ & & & $8.78, \mathrm{~d}(4.7)$ \\
\hline \multicolumn{6}{|l|}{$\mathrm{OBz}$} \\
\hline 2,6 & & & $7.89, \mathrm{~d}(8.2)$ & $7.88, \mathrm{~d}(7.8)$ & $7.95, \mathrm{~d}(7.3)$ \\
\hline 3,5 & & & $7.41, \mathrm{t}(7.8)$ & $7.34, \mathrm{t}(7.6)$ & $7.47, \mathrm{t}(7.8)$ \\
\hline 4 & & & $7.53, \mathrm{t}(7.4)$ & $7.47, \mathrm{t}(7.2)$ & $7.59, \mathrm{t}(7.4)$ \\
\hline
\end{tabular}

$8, \mathrm{H}_{3}-18$, and $\mathrm{H}_{3}-19$ indicated a premyrsinane skeleton without the ether functionality between $\mathrm{C}-17$ and C-13. The locations of the ester groups were established from the HMBC correlations from $\delta_{\mathrm{C}} 176.0$ to $\delta_{\mathrm{H}} 5.39(\mathrm{H}-3) ; \delta_{\mathrm{C}} 164.9$ to $\delta_{\mathrm{H}} 6.42(\mathrm{H}-5) ; \delta_{\mathrm{C}}$ 164.7 to $\delta_{\mathrm{H}} 5.04(\mathrm{H}-17)$; and $\delta_{\mathrm{C}} 170.0$ to $\delta_{\mathrm{H}} 5.01(\mathrm{H}-7)$ and indicated that isobutanoyl, benzoyl, nicotinyl, and acetyl groups occurred at C-3, C-5, C-7, and C-17, respectively. The chemical shift at $\delta_{\mathrm{C}-15} 84.1$ indicated clearly a hydroxy group at C-15, and the last acetyl group was placed at C-13. NOESY experiments led to the assignment of the configuration of the molecule. Starting from the $\alpha$-orientation of $\mathrm{H}-4$, cross-peaks between $\mathrm{H}-4 / \mathrm{H}-3, \mathrm{H}-$
4/H-2, H-4/H-17a, $\mathrm{H}-4 / \mathrm{H}_{3}-20$, and $\mathrm{H}-20 / \mathrm{H}-11$ demonstrated the $\alpha$-orientation of these protons. The NOE effects observed between $\mathrm{H}-5 / \mathrm{H}-12$ and $\mathrm{H}-5 / \mathrm{OH}-15$ indicated the $\beta$-orientation of $\mathrm{H}-5, \mathrm{H}-12$, and $\mathrm{OH}-15$. Consequently, the data obtained supported the proposed structure of 19 (falcatin $S$ ) as $7 \beta, 13 \beta-O$ diacetyl-5 $\alpha$-O-benzoyl-15 $\beta$-hydroxy-3 $\beta$-O-isobutanoyl- $17 \alpha-O$ nicotinylpremyrsinol.

Compound 20 was found to be identical in all of its characteristics, including the ${ }^{1} \mathrm{H}$ NMR and mass spectrometric data, with euphorprolitherin D, isolated earlier from Euphorbia prolifera by Zhang et al. in $2004 .^{33}$ 
Table 6. ${ }^{13} \mathrm{C}$ NMR Data $\left(\delta_{\mathrm{C}}\right)$ of Compounds $13-19\left(\mathrm{CDCl}_{3}, 125 \mathrm{MHz}^{a}\right.$ or $\left.150 \mathrm{MHz}^{b}\right)$

\begin{tabular}{|c|c|c|c|c|c|c|c|}
\hline position & $13^{a}$ & $14^{a}$ & $15^{a}$ & $16^{b}$ & $17^{a}$ & $18^{a}$ & $19^{a}$ \\
\hline 1 & 48.3, $\mathrm{CH}_{2}$ & $48.8, \mathrm{CH}_{2}$ & 49.1, $\mathrm{CH}_{2}$ & 44.3, $\mathrm{CH}_{2}$ & 44.3, $\mathrm{CH}_{2}$ & $44.2, \mathrm{CH}_{2}$ & 42.9, $\mathrm{CH}_{2}$ \\
\hline 2 & $84.2, \mathrm{C}$ & $84.2, \mathrm{C}$ & 83.6, C & $35.9, \mathrm{CH}$ & $36.2, \mathrm{CH}$ & $35.7, \mathrm{CH}$ & 37.1, CH \\
\hline 3 & 78.1, CH & 78.4, CH & 78.2, CH & 76.4, $\mathrm{CH}$ & 76.6, CH & $76.5, \mathrm{CH}$ & 77.9, CH \\
\hline 4 & 47.0, CH & 48.6, $\mathrm{CH}$ & 48.6, $\mathrm{CH}$ & $53.2, \mathrm{CH}$ & $53.4, \mathrm{CH}$ & $53.5, \mathrm{CH}$ & $50.5, \mathrm{CH}$ \\
\hline 5 & $68.4, \mathrm{CH}$ & $68.9, \mathrm{CH}$ & $68.9, \mathrm{CH}$ & $67.1, \mathrm{CH}$ & $67.4, \mathrm{CH}$ & $67.4, \mathrm{CH}$ & 69.9, CH \\
\hline 6 & $62.0, \mathrm{C}$ & $62.2, \mathrm{C}$ & $62.2, \mathrm{C}$ & $55.9, \mathrm{C}$ & $56.1, \mathrm{C}$ & 55.6, C & 48.1, C \\
\hline 7 & 204.3, C & 204.5, C & 204.6, C & 72.6, CH & $72.9, \mathrm{CH}$ & 73.1, CH & $70.5, \mathrm{CH}$ \\
\hline 8 & $70.8, \mathrm{CH}$ & $70.9, \mathrm{CH}$ & $70.9, \mathrm{CH}$ & 25.6, $\mathrm{CH}_{2}$ & 22.9, $\mathrm{CH}_{2}$ & 22.9, $\mathrm{CH}_{2}$ & 22.2, $\mathrm{CH}_{2}$ \\
\hline 9 & 29.9, CH & $30.0, \mathrm{CH}$ & 30.1, CH & 23.6, CH & 23.4, CH & 23.2, CH & 23.8, CH \\
\hline 10 & 77.5, C & $77.5, \mathrm{C}$ & 77.6, C & 19.1, C & 19.1, C & 19.3, C & 18.3, C \\
\hline 11 & $41.5, \mathrm{CH}$ & 41.3, CH & $41.3, \mathrm{CH}$ & $18.5, \mathrm{CH}$ & $18.5, \mathrm{CH}$ & 18.6, CH & $18.3, \mathrm{CH}$ \\
\hline 12 & 41.3, CH & $41.5, \mathrm{CH}$ & 41.5, CH & 38.1, CH & $37.8, \mathrm{CH}$ & $37.9, \mathrm{CH}$ & $35.3, \mathrm{CH}$ \\
\hline 13 & $89.1, \mathrm{C}$ & $88.7, \mathrm{C}$ & $88.8, \mathrm{C}$ & $87.8, \mathrm{C}$ & $88.6, \mathrm{C}$ & 88.1, C & $85.5, \mathrm{C}$ \\
\hline 14 & $81.5, \mathrm{CH}$ & $80.8, \mathrm{CH}$ & $80.9, \mathrm{CH}$ & 79.7, CH & $80.4, \mathrm{CH}$ & $80.2, \mathrm{CH}$ & 204.0, C \\
\hline 15 & $88.5, \mathrm{C}$ & 89.3, C & $89.3, \mathrm{C}$ & $89.8, \mathrm{C}$ & $89.8, \mathrm{C}$ & $89.8, \mathrm{C}$ & 84.1, C \\
\hline 16 & 24.7, $\mathrm{CH}_{3}$ & 25.6, $\mathrm{CH}_{3}$ & 25.5, $\mathrm{CH}_{3}$ & 14.2, $\mathrm{CH}_{3}$ & 14.6, $\mathrm{CH}_{3}$ & 14.4, $\mathrm{CH}_{3}$ & 13.7, $\mathrm{CH}_{3}$ \\
\hline 17 & 67.1, $\mathrm{CH}_{2}$ & 67.0, $\mathrm{CH}_{2}$ & 67.0, $\mathrm{CH}_{2}$ & 97.1, CH & $97.3, \mathrm{CH}$ & 97.1, CH & 63.6, $\mathrm{CH}_{2}$ \\
\hline 18 & $24.4, \mathrm{CH}_{3}$ & 24.6, $\mathrm{CH}_{3}$ & $24.6, \mathrm{CH}_{3}$ & $15.8, \mathrm{CH}_{3}$ & 16.6, $\mathrm{CH}_{3}$ & 16.1, $\mathrm{CH}_{3}$ & $14.8, \mathrm{CH}_{3}$ \\
\hline 19 & 34.6, $\mathrm{CH}_{2}$ & 34.6, $\mathrm{CH}_{2}$ & 34.7, $\mathrm{CH}_{2}$ & 28.1, $\mathrm{CH}_{3}$ & 28.3, $\mathrm{CH}_{3}$ & 28.1, $\mathrm{CH}_{3}$ & 29.4, $\mathrm{CH}_{3}$ \\
\hline 20 & 22.2, $\mathrm{CH}_{3}$ & 22.3, $\mathrm{CH}_{3}$ & $22.2, \mathrm{CH}_{3}$ & $24.8, \mathrm{CH}_{3}$ & 25.1, $\mathrm{CH}_{3}$ & $25.0, \mathrm{CH}_{3}$ & 24.9, $\mathrm{CH}_{3}$ \\
\hline OProp-3 1 & & 173.0, C & 173.0, C & & & 174.0, C & \\
\hline 2 & & 27.3, $\mathrm{CH}_{2}$ & 27.3, $\mathrm{CH}_{2}$ & & & 27.6, $\mathrm{CH}_{2}$ & \\
\hline 3 & & 8.6, $\mathrm{CH}_{3}$ & $8.5, \mathrm{CH}_{3}$ & & & 9.0, $\mathrm{CH}_{3}$ & \\
\hline OiBu-3 1 & 175.3, C & & & $176.8, \mathrm{C}$ & & & 176.0, C \\
\hline 2 & $34.0, \mathrm{CH}$ & & & $34.3, \mathrm{CH}$ & & & 34.1, CH \\
\hline 3 & 18.2, $\mathrm{CH}_{3}$ & & & $19.5, \mathrm{CH}_{3}$ & & & 19.2, $\mathrm{CH}_{3}$ \\
\hline 4 & 18.9, $\mathrm{CH}_{3}$ & & & 18.6, $\mathrm{CH}_{3}$ & & & 18.4, $\mathrm{CH}_{3}$ \\
\hline OAc-5 & 169.7, C & 169.9, C & 170.2, C & 169.2, C & 168.9, C & 169.1, C & \\
\hline OAc-7 & $20.8, \mathrm{CH}_{3}$ & 20.8, $\mathrm{CH}_{3}$ & 20.3, $\mathrm{CH}_{3}$ & 21.2, $\mathrm{CH}_{3}$ & 21.5, $\mathrm{CH}_{3}$ & 21.4, $\mathrm{CH}_{3}$ & $\begin{array}{l}\text { 170.0, C } \\
21.3, \mathrm{CH}_{3}\end{array}$ \\
\hline OAc-10 & 168.7, C & 168.7, C & 168.8, C & & & & \\
\hline & $21.5, \mathrm{CH}_{3}$ & 21.2, $\mathrm{CH}_{3}$ & 21.5, $\mathrm{CH}_{3}$ & & & & \\
\hline OAc-13 & & & & & & & $\begin{array}{l}\text { 170.6, C } \\
21.3, \mathrm{CH}_{3}\end{array}$ \\
\hline OAc-14 & $\begin{array}{l}\text { 170.2, C } \\
21.2, \mathrm{CH}_{3}\end{array}$ & $\begin{array}{l}\text { 170.1, C } \\
21.2, \mathrm{CH}_{3}\end{array}$ & $\begin{array}{l}\text { 170.0, C } \\
21.3, \mathrm{CH}_{3}\end{array}$ & $\begin{array}{l}\text { 170.2, C } \\
21.0, \mathrm{CH}_{3}\end{array}$ & & & \\
\hline OAc-15 & 168.1, C & 168.1, C & 168.5, C & $168.4, \mathrm{C}$ & 167.9, C & 167.9, C & \\
\hline & 22.9, $\mathrm{CH}_{3}$ & 22.3, $\mathrm{CH}_{3}$ & $20.9, \mathrm{CH}_{3}$ & 23.0, $\mathrm{CH}_{3}$ & 23.0, $\mathrm{CH}_{3}$ & 22.9, $\mathrm{CH}_{3}$ & \\
\hline OAc-17 & & & & $\begin{array}{l}\text { 170.0, C } \\
21.4, \mathrm{CH}_{3}\end{array}$ & $\begin{array}{l}\text { 170.0, C } \\
21.6, \mathrm{CH}_{3}\end{array}$ & $\begin{array}{l}169.8, \mathrm{C} \\
21.4, \mathrm{CH}_{3}\end{array}$ & \\
\hline OiBu 1 & 175.0, C & 174.9, C & & & 176.5, C & & \\
\hline 2 & $34.3, \mathrm{CH}$ & $34.4, \mathrm{CH}$ & & & $34.5, \mathrm{CH}$ & & \\
\hline 3 & 18.4, $\mathrm{CH}_{3}$ & 20.3, $\mathrm{CH}_{3}$ & & & 19.1, $\mathrm{CH}_{3}$ & & \\
\hline 4 & 20.3, $\mathrm{CH}_{3}$ & $18.5, \mathrm{CH}_{3}$ & & & $18.8, \mathrm{CH}_{3}$ & & \\
\hline OMeBu-8 1 & & & 174.9, C & & & & \\
\hline 2 & & & $34.9, \mathrm{CH}$ & & & & \\
\hline 3 & & & 18.5, $\mathrm{CH}_{2}$ & & & & \\
\hline 4 & & & 14.1, $\mathrm{CH}_{3}$ & & & & \\
\hline 5 & & & 20.3, $\mathrm{CH}_{3}$ & & & & \\
\hline $\mathrm{OBz} C \mathrm{O}$ & & & 164.7, C & 166.1, C & 165.3, C & 165.5, C & 164.9, C \\
\hline 1 & & & 129.4, C & 129.9, C & 130.0, C & 129.6, C & 129.3, C \\
\hline 2,6 & & & $128.3, \mathrm{CH}$ & $128.3, \mathrm{CH}$ & $128.6, \mathrm{CH}$ & $128.4, \mathrm{CH}$ & 127.9, CH \\
\hline 3,5 & & & 133.0, CH & $133.1, \mathrm{CH}$ & $133.3, \mathrm{CH}$ & 133.1, CH & 132.7, CH \\
\hline 4 & & & 130.5, CH & $130.3, \mathrm{CH}$ & 129.7, CH & 129.4, CH & 129.4, CH \\
\hline ONic 1 & 163.4, C & 163.4, C & & & 164.4, C & $164.8, \mathrm{C}$ & 164.7, C \\
\hline 2 & $150.7, \mathrm{CH}$ & $150.4, \mathrm{CH}$ & & & $151.3, \mathrm{CH}$ & $150.7, \mathrm{CH}$ & $150.4, \mathrm{CH}$ \\
\hline 3 & 126.2, CH & 126.6, CH & & & $124.8, \mathrm{CH}$ & 128.3, CH & 125.1, CH \\
\hline 4 & 137.0, CH & 137.0, CH & & & 137.5, CH & 137.2, CH & 136.1, CH \\
\hline 5 & 123.2, CH & 123.4, CH & & & 123.3, CH & 123.2, CH & 123.0, CH \\
\hline 6 & 153.4, CH & 153.4, CH & & & 153.8, CH & 153.6, CH & 153.0, CH \\
\hline
\end{tabular}


Table 7. ${ }^{1} \mathrm{H}$ NMR Data $\left(\delta_{\mathrm{H}}\right)$ of Compounds 18 and 19 $\left(\mathrm{CDCl}_{3}, 500 \mathrm{MHz}\right)$

\begin{tabular}{|c|c|c|}
\hline position & 18 & 19 \\
\hline $1 \alpha$ & 2.81, dd $(16.1,9.6)$ & 3.19 , dd $(13.6,7.8)$ \\
\hline $1 \beta$ & 2.63, dd $(16.1,9.6)$ & $1.65, \mathrm{~m}$ \\
\hline 2 & $2.20, \mathrm{~m}$ & $1.87, \mathrm{~m}$ \\
\hline 3 & $5.13, \mathrm{t}(3.9)$ & $5.39, \mathrm{~d}(3.5)$ \\
\hline 4 & 3.15 , dd $(10.6,3.7)$ & 2.44 , dd $(11.6,3.5)$ \\
\hline 5 & $5.88, \mathrm{~d}(10.6)$ & $6.42, \mathrm{~d}(11.6)$ \\
\hline 7 & 5.43 , dd $(10.8,3.3)$ & $5.01, \mathrm{~m}$ \\
\hline \multirow[t]{2}{*}{8} & $2.12, \mathrm{~m}$ & $2,16, \mathrm{~m}$ \\
\hline & $1.67, \mathrm{~m}$ & $1.93, \mathrm{~m}$ \\
\hline 9 & $1.04, \mathrm{~m}$ & $0.78, \mathrm{~m}$ \\
\hline 11 & $0.88, \mathrm{t}(7.7)$ & $0.78, \mathrm{~m}$ \\
\hline 12 & $2.91, \mathrm{~d}(7.2)$ & $3.61, \mathrm{~d}(6.2)$ \\
\hline 14 & $5.29, \mathrm{~s}$ & \\
\hline 16 & $0.76, \mathrm{~d}(6.8)$ & $0.86, \mathrm{~d}(6.5)$ \\
\hline $17 \mathrm{a}$ & $6.48, \mathrm{~s}$ & $5.04, \mathrm{~d}(11.6)$ \\
\hline $17 \mathrm{~b}$ & & $4.56, \mathrm{~d}(11.6)$ \\
\hline 18 & $1.28, \mathrm{~s}$ & $1.08, \mathrm{~s}$ \\
\hline 19 & $1.18, \mathrm{~s}$ & $0.98, \mathrm{~s}$ \\
\hline 20 & $1.36, \mathrm{~s}$ & $1.78, \mathrm{~s}$ \\
\hline OAc-5 & $1.38, \mathrm{~s}$ & $1.94, \mathrm{~s}$ \\
\hline OAc-7 & & $2.16, \mathrm{~s}$ \\
\hline OAc-13 & & $2.14, \mathrm{~s}$ \\
\hline OAc- 15 & $2.07, \mathrm{~s}$ & \\
\hline OAc-17 & $2.23, \mathrm{~s}$ & \\
\hline \multicolumn{3}{|l|}{ OProp-3 } \\
\hline \multirow[t]{2}{*}{2} & $2.32, \mathrm{~m}$ & \\
\hline & $2.22, \mathrm{dq}(16.5,7.6)$ & \\
\hline 3 & $1.07, \mathrm{t}(7.6)$ & \\
\hline \multicolumn{3}{|l|}{$\mathrm{OiBu}$} \\
\hline 2 & & 2.49 , sept (7.0) \\
\hline 3 & & $1.14, \mathrm{~d}(7.0)$ \\
\hline 4 & & $0.96, \mathrm{~d}(7.0)$ \\
\hline \multicolumn{3}{|l|}{$\mathrm{OBz}$} \\
\hline 2,6 & $7.95, \mathrm{~d}(7.4)$ & $7.70, \mathrm{~d}(7.4)$ \\
\hline 3,5 & $7.47, \mathrm{t}(7.8)$ & $7.03, \mathrm{t}(7.7)$ \\
\hline 4 & $7.59, \mathrm{t}(7.4)$ & $7.16, \mathrm{t}(7.3)$ \\
\hline \multicolumn{3}{|l|}{ ONic } \\
\hline 2 & $9.15, \mathrm{~s}$ & $8.84, \mathrm{~d}(1.3)$ \\
\hline 4 & $8.24, \mathrm{~d}(7.6)$ & $7.61, \mathrm{dt}(7.9,1.3)$ \\
\hline 5 & 7.39, dd $(7.6,4.9)$ & $7.00, \mathrm{dd}(8.0,4.7)$ \\
\hline 6 & $8.78, \mathrm{~d}(4.9)$ & 8.54 , dd $(4.7,1.3)$ \\
\hline $15-\mathrm{OH}$ & & $4.38, \mathrm{~s}$ \\
\hline
\end{tabular}

Effects of the Investigated Compounds on GIRK and hERG Potassium Channels. In order to study the possible potassium channel-blocking capability of the investigated compounds, screening of the isolated diterpenes with different skeletons and substitution patterns was performed on a GIRK channel expressing cell line. Myrsinane, premyrsinane, and cyclomyrsinane diterpenes substituted with hydroxy, acetyl, propanoyl, isobutanoyl, 2-methylbutanoyl, $n$-hexanoyl, benzoyl, and nicotinyl ester groups were included in the bioassay. Compounds were screened at two concentrations ( 1 and $10 \mu \mathrm{M})$ on two to three cells.

Thirteen of the tested compounds $(1-3,8,9,12,14,15$, and 21-24) were found to possess blocking activity (i.e., at least $60 \%$ decrease in the current at $10 \mu \mathrm{M}$ concentration) on GIRK channels. All compounds were also tested against the HEKhERG (human embryonic kidney cells) cell line, and the
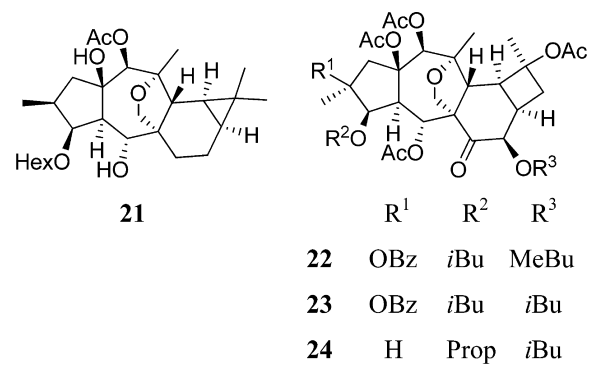

selectivity of their GIRK blocking effect was evaluated with these experiments. Selectivity studies were performed at three concentrations $(3,10$, and $30 \mu \mathrm{M})$ on two or three cells. Five out of the 13 compounds, falcatins A-C (1-3), falcatin $\mathrm{H}(\mathbf{8})$, and falcatin I (9), which were potent for GIRK channels, exerted low inhibitory effects on the hERG channel (i.e., a maximum $20 \%$ decrease in the current at $10 \mu \mathrm{M}$ concentration). Results of the GIRK screening and the selectivity investigations on hERG are shown in Table 8.

Table 8. GIRK- and hERG-Inhibitory Effects of Compounds Isolated from E. falcata

\begin{tabular}{|c|c|c|c|c|c|}
\hline \multirow[b]{3}{*}{ compound } & \multicolumn{5}{|c|}{ inhibition (\%) } \\
\hline & \multicolumn{2}{|c|}{ GIRK } & \multicolumn{3}{|c|}{ hERG } \\
\hline & $1 \mu \mathrm{M}$ & $10 \mu \mathrm{M}$ & $3 \mu \mathrm{M}$ & $10 \mu \mathrm{M}$ & $30 \mu \mathrm{M}$ \\
\hline 1 & 43 & 83 & 9 & 20 & 39 \\
\hline 2 & 24 & 62 & 5 & 13 & 18 \\
\hline 3 & 34 & 69 & 0 & 4 & 16 \\
\hline 4 & 21 & 47 & 11 & 24 & 40 \\
\hline 5 & 26 & 61 & 13 & 24 & 43 \\
\hline 6 & 21 & 54 & 20 & 33 & 46 \\
\hline 8 & 28 & 61 & 8 & 16 & 23 \\
\hline 9 & 31 & 72 & 4 & 14 & 25 \\
\hline 10 & 11 & 24 & 8 & 20 & 33 \\
\hline 11 & 14 & 26 & 12 & 22 & 32 \\
\hline 12 & 23 & 69 & 20 & 54 & 82 \\
\hline 13 & 8 & 57 & 8 & 19 & 30 \\
\hline 14 & 35 & 65 & 11 & 22 & 42 \\
\hline 15 & 20 & 64 & 16 & 31 & 52 \\
\hline 17 & 18 & 37 & 48 & 68 & 78 \\
\hline 19 & 28 & 48 & 14 & 29 & 53 \\
\hline 20 & 19 & 54 & 12 & 21 & 45 \\
\hline 21 & 30 & 69 & 19 & 40 & 55 \\
\hline 22 & 26 & 70 & 14 & 30 & 40 \\
\hline 23 & 33 & 77 & 14 & 24 & 53 \\
\hline 24 & 30 & 70 & 0 & 23 & 33 \\
\hline
\end{tabular}

Compounds with a myrsinane skeleton and with a carbonyl function at C-7 (1-3) were found to be highly active and selective inhibitors. In addition, esters of 2-deoxycyclomyrsinane with an aliphatic ester group at C-8 (8 and 9$)$ were also found to have selective ion channel activity. These compounds showing GIRK selectivity were subjected to further investigations. The dose-response curves of these five compounds on the GIRK channel were determined in detailed experiments where the effect of the compounds was tested at four concentrations on at least five cells. Dose-response curves and $\mathrm{IC}_{50}$ values of these compounds are shown in Figure 5.

Falcatin A (1) was the most promising agent, with an $\mathrm{IC}_{50}$ value of $2.5 \pm 0.2 \mu \mathrm{M}$. The $\mathrm{IC}_{50}$ values of falcatins $\mathrm{C}(3)$ and I (9) were very similar $(4.7 \pm 0.3$ and $4.9 \pm 0.2 \mu \mathrm{M}$, respectively $)$. In 


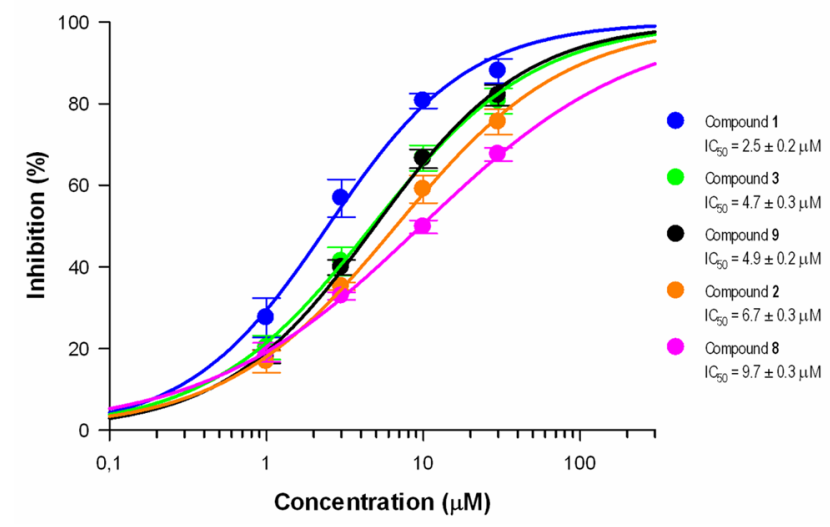

Figure 5. Dose-response curves of compounds 1-3, 8, and 9 on GIRK channel inhibitory activity.

turn, the $\mathrm{IC}_{50}$ value of falcatin $\mathrm{B}(2)$ was $6.7 \pm 0.3 \mu \mathrm{M}$, whereas that of falcatin $\mathrm{H}(8)$ was determined to be $9.7 \pm 0.3 \mu \mathrm{M}$. Sample current curves and time course of the hERG and GIRK current amplitude during the application of different concentrations of the most effective compound (falcatin A, 1) are shown in Figure 6.

\section{CONCLUSIONS}

Nineteen new diterpenes, falcatins A-S (1-19), and the known compound euphorprolitherin D (20) were isolated from the whole plants of E. falcata. The new compounds were identified as tetra-, penta-, hexa-, and heptaesters of the myrsinane, premyrsinane, and cyclomyrsinane polyols acylated with acetyl, propanoyl, isobutanoyl, 2-methylbutanoyl, benzoyl, and nicotinyl acids. Falcatins D-F (4-6) contain a rare 10,13-epoxy functionality in their myrsinane structure. Moreover, falcatins L$\mathrm{O}(\mathbf{1 2}-15)$ are substituted with an ester group, and falcatins J and $\mathrm{K}(10$ and 11$)$ possess a hydroxy group at C-2. This subclass of the cyclomyrsinanes has been found only in E. falcata so far. Biogenetically, naturally occurring myrsinanes and cyclomyrsinanes can be derived from lathyranes through premyrsinanes by intramolecular cyclization. ${ }^{34}$ Myrsinol-related diterpenes are specific to the genus Euphorbia; up to now more than 110 such compounds, including myrsinanes $(n=58)$, premyrsinanes $(n=39)$, and cyclomyrsinanes $(n=19)$, were isolated from 15 Euphorbia species (E. aellenii, E. aleppica, E. boetica, E. cheiradenia, E. decipiens, E. falcata, E. kopetdaghi, E. macroclada, E. microsciadia, E. myrsinites, E. pithyusa subsp. cupanii, E. prolifera, E. splendida, E. seguieriana, and E. teheranica). ${ }^{22,35-39}$ Among them, the presence of all three types of myrsinanes has been reported only from E. prolifera, E. seguieriana, and E. falcata. The richest source of diterpenes seems to be E. prolifera; to date, 46 such compounds were isolated from the plant, and tiglianeand lathyrane-type diterpenes were also identified along with myrsinols. ${ }^{40,41}$ Moreover, in our study three compounds (4-6) with a rearranged tetrahydrofuran ring were also isolated from $E$. falcata. Previously this type of diterpene was detected in only two species (E. decipiens and E. cheiradenia). ${ }^{30-32}$
A
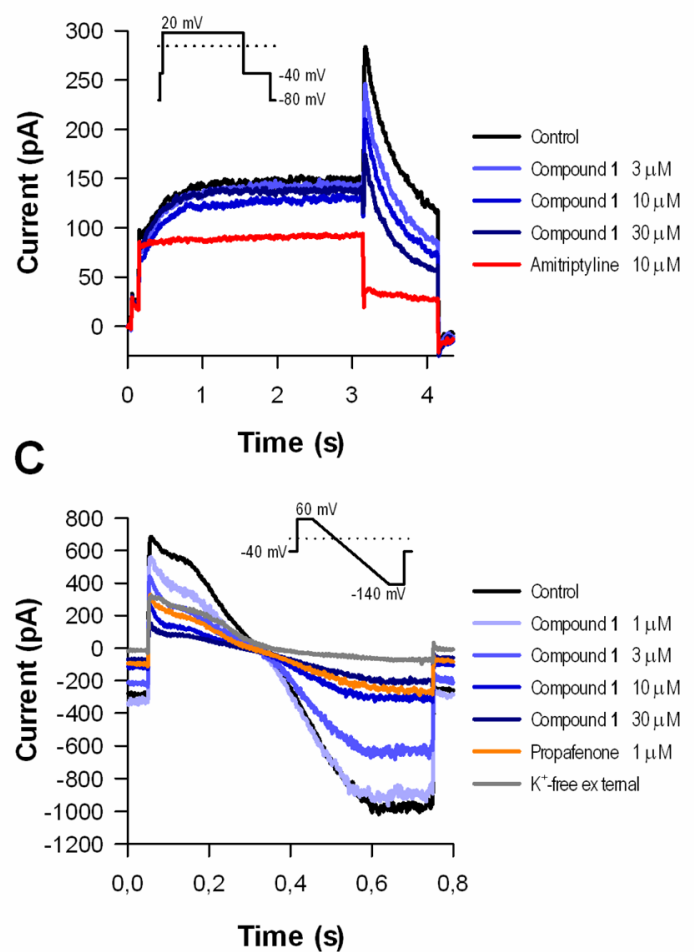

B
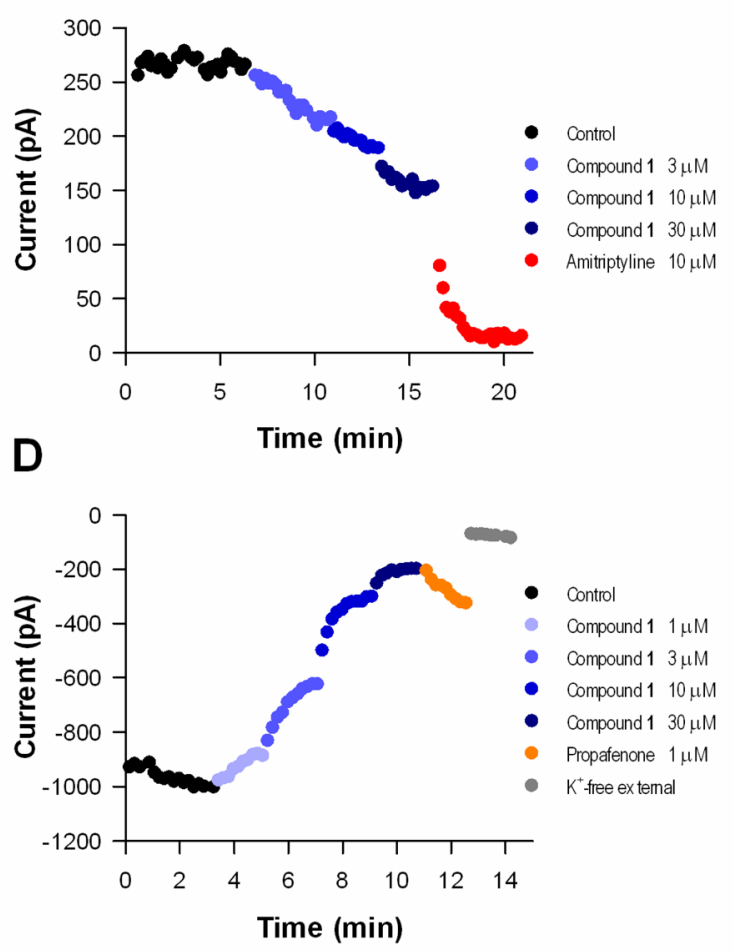

Figure 6. Effects of compound 1 on the hERG and GIRK current. (A) Representative hERG current curves recorded during the application of 3, 10, and $30 \mu \mathrm{M}$ compound $\mathbf{1}$. The inset shows the applied hERG voltage protocol. (B) Time-course of the hERG current amplitude. (C) Typical GIRK current curves obtained after the application of $1,3,10$, and $30 \mu \mathrm{M}$ compound $\mathbf{1}$. The inset shows the applied GIRK voltage protocol. (D) Illustrative time series showing the GIRK inward current values. 
Myrsinane-related diterpenes are interesting targets of natural product based drug discovery programs. Recently, their antiangiogenic, immunomodulatory, immunosuppressive, neuroprotective, LPS-induced NO production inhibitory, MDR reversal, cytotoxic, DNA-damaging, antipyretic-analgesic, prolyl endopeptidase inhibitory, and urease inhibitory activities have been reported. ${ }^{25,35-38,42-46}$ This is the first time that selective GIRK channel inhibitory activity of natural diterpenes has been investigated.

In the present study, myrsinane, cyclomyrsinane, and premyrsinane diterpenes were studied on stable transfected HEK-hERG (Kv11.1) and HEK-GIRK1/4 (Kir3.1 and Kir3.4) cells. Blocking activity on the GIRK channel was exerted by 13 compounds (1-3, 8, 9, 12, 14, 15, and 21-24) (61-83\% at 10 $\mu \mathrm{M})$, and, among them, five [falcatins $\mathrm{A}-\mathrm{C}(1-3)$, falcatin $\mathrm{H}$ (8), and falcatin I (9)] showed low potencies on hERG channels (4-20\% at $10 \mu \mathrm{M})$. These compounds with selective activities on GIRK channels are potential lead compounds for the treatment of atrial fibrillation. The electrophysiological screening of structurally diverse diterpenes did not permit a detailed structure-activity relationship determination, but it was observed that the most promising compounds, 1-3, are myrsinanes with a carbonyl function at C-7, an ether bridge between $\mathrm{C}-17$ and C-13, and no epoxy functionality between C10 and C-13. Another group of promising GIRK ion channel inhibitory compounds was established as 2-deoxycyclomyrsinanes with an aliphatic ester at C-8 (compounds $\mathbf{8}$ and 9).

\section{EXPERIMENTAL SECTION}

General Experimental Procedures. Optical rotations were measured in $\mathrm{CHCl}_{3}$ using a PerkinElmer 341 polarimeter. NMR spectra were recorded in $\mathrm{CDCl}_{3}$ on a Bruker Avance DRX 500 spectrometer at $500 \mathrm{MHz}\left({ }^{1} \mathrm{H}\right)$ and $125 \mathrm{MHz}\left({ }^{13} \mathrm{C}\right)$ and a Bruker Ultrashield Plus 600 spectrometer at $600 \mathrm{MHz}\left({ }^{1} \mathrm{H}\right)$ and $150 \mathrm{MHz}\left({ }^{13} \mathrm{C}\right)$, using the signals of deuterated solvents as references. Two-dimensional NMR data were acquired and processed with standard Bruker software. Gradientenhanced versions of the experiments were used. High-resolution MS data were recorded on a Waters-Micromass Q-TOF Premier mass spectrometer equipped with an electrospray source. The resolution was over $1 \mathrm{ppm}$. The data were acquired and processed with MassLynx software. Column chromatography (CC) was carried out on polyamide (ICN); vacuum liquid chromatography (VLC) on silica gel G $(15 \mu \mathrm{m}$, Merck); preparative thin-layer chromatography (preparative TLC) on silica gel $60 \mathrm{~F}_{254}$ and $\mathrm{RP}-18 \mathrm{~F}_{254}$ plates (Merck); rotation planar chromatography (RPC) on silica gel $60 \mathrm{GF}_{254}$ with a Chromatotron instrument (Harrison Research); and reversed-phase HPLC on a LiChrospher RP-18 $(5 \mu \mathrm{m}, 250 \times 4 \mathrm{~mm}$, Merck $)$ column with a Waters 600 instrument with detection at $254 \mathrm{~nm}$.

Plant Material. Euphorbia falcata was collected in September 2008 in Mosonmagyaróvár (Hungary). The plant material was identified by one of the authors (G.P.). A voucher specimen (No. 775) has been deposited at the Herbarium of the Department of Pharmacognosy, University of Szeged, Szeged, Hungary.

Extraction and Isolation. The fresh plant material $(20 \mathrm{~kg})$, which was stored at $-20{ }^{\circ} \mathrm{C}$ before processing, was crushed in a blender and then percolated with $\mathrm{MeOH}(178 \mathrm{~L})$ at room temperature. The crude extract was concentrated in vacuo and subjected to solvent-solvent partitioning with $\mathrm{CHCl}_{3}(30 \mathrm{~L})$. On evaporation, an organic-phase residue of $344 \mathrm{~g}$ was obtained, which was chromatographed over a polyamide column $(1100 \mathrm{~g})$ with mixtures of $\mathrm{H}_{2} \mathrm{O}-\mathrm{MeOH}(4: 1,3: 2$, 2:3, and 1:4) as eluents. The fractions obtained with $\mathrm{H}_{2} \mathrm{O}-\mathrm{MeOH}$ (4:1 and 3:2) were combined and subjected to silica gel VLC, using a gradient system of cyclohexane-EtOAc- $\mathrm{MeOH}$ (from 8:2:0 to 0:0:1). The CC fractions were combined into six fractions according to the TLC monitoring (fractions 1-6). Fraction 3, eluted with cyclohexaneEtOAc (7:3), was separated by RPC with cyclohexane- $\mathrm{CH}_{2} \mathrm{Cl}_{2}-$
$\mathrm{MeOH}$ of increasing polarity (from 8:2:0 to 60:50:3). Subfraction 3/3, eluted with cyclohexane- $\mathrm{CH}_{2} \mathrm{Cl}_{2}-\mathrm{MeOH}$ (60:30:2), was purified further by RP-VLC ( $\mathrm{MeOH}-\mathrm{H}_{2} \mathrm{O}$ from 1:1 to $\left.85: 15\right)$ and finally by NPTLC with $\mathrm{CHCl}_{3}$-acetone $(98: 2)$ to yield falcatin $\mathrm{P}(16)(1.4 \mathrm{mg})$. Fraction 4, obtained with cyclohexane-EtOAc- $\mathrm{MeOH}$ (70:30:2), was further separated by RPC with a cyclohexane- $\mathrm{CH}_{2} \mathrm{Cl}_{2}-\mathrm{MeOH}$ (from 60:30:2 to 50:50:4) gradient system. Subfraction 4/3 eluted with cyclohexane- $\mathrm{CH}_{2} \mathrm{Cl}_{2}-\mathrm{MeOH}(60: 40: 3)$ was purified by NP-TLC with $n$-hexane-acetone (3:2), then by RP-HPLC with $\mathrm{MeOH}-\mathrm{H}_{2} \mathrm{O}(3: 1)$ as eluent, at a flow rate of $0.5 \mathrm{~mL} / \mathrm{min}$, to afford falcatin $\mathrm{G}(7)(1.1 \mathrm{mg})$ at $t_{\mathrm{R}} 30.3 \mathrm{~min}$. Fraction 5, obtained with cyclohexane-EtOAc-MeOH (70:30:2), was subjected to RPC, eluted with cyclohexane- $-\mathrm{CH}_{2} \mathrm{Cl}_{2}-$ $\mathrm{MeOH}$ mixtures of increasing polarity (from 70:20:1 to 5:5:1). Subfraction 5/3, eluted with cyclohexane- $\mathrm{CH}_{2} \mathrm{Cl}_{2}-\mathrm{MeOH}$ (60:30:2), was further separated on RP-VLC using a $\mathrm{MeOH}-\mathrm{H}_{2} \mathrm{O}$ (from 1:1 to 9:1) gradient system as eluent. Subfraction 5/3/2, eluted with $\mathrm{MeOH}-$ $\mathrm{H}_{2} \mathrm{O}$ (1:1), was purified further by NP-TLC, with toluene-acetone (9:1) as developing system, to yield falcatin C (3) (46.3 mg). Subfraction $5 / 3 / 3$, eluted with $\mathrm{MeOH}-\mathrm{H}_{2} \mathrm{O}$ (3:2), was separated by RP-TLC with $\mathrm{MeOH}-\mathrm{H}_{2} \mathrm{O}(9: 1)$ to afford falcatin B (2) (3.3 mg). Subfraction 5/3/4, eluted with $\mathrm{MeOH}-\mathrm{H}_{2} \mathrm{O}(7: 3)$, was purified by NPTLC with toluene-acetone $(4: 1)$ to yield falcatin $\mathrm{H}(8)(6.3 \mathrm{mg})$ and falcatin $\mathrm{O}(15)(12.3 \mathrm{mg})$. Subfraction 5/3/5, eluted with $\mathrm{MeOH}-\mathrm{H}_{2} \mathrm{O}$ (7:3 and 8:2), was separated by NP-TLC with cyclohexane- $-\mathrm{CH}_{2} \mathrm{Cl}_{2}-$ $\mathrm{MeOH}$ (5:15:1), to yield falcatin K (11) $(5.5 \mathrm{mg})$, falcatin F (6) (2.5 $\mathrm{mg})$, and euphorprolitherin $\mathrm{D}(\mathbf{2 0})(2.9 \mathrm{mg})$. The compound observed at $R_{f} 0.6$ was further purified by RP-HPLC, eluted with $\mathrm{MeOH}-\mathrm{H}_{2} \mathrm{O}$ $(7: 3)$ at a flow rate of $1 \mathrm{~mL} / \mathrm{min}$, to afford falcatin $\mathrm{D}(4)(6.7 \mathrm{mg})\left(t_{\mathrm{R}}\right.$ $11.2 \mathrm{~min})$. Fraction 6 , eluted with cyclohexane-EtOAc-MeOH (20:10:1), was rechromatographed by NP-VLC with cyclohexaneEtOAc-MeOH (from 6:2:0 to 1:1:1). Subfraction 6/4, eluted with cyclohexane-EtOAc-MeOH (5:5:1), was further separated by RPC with cyclohexane- $\mathrm{CH}_{2} \mathrm{Cl}_{2}-\mathrm{MeOH}$ (from 5:15:0 to 15:45:15) as the eluent system. Subfractions yielded with mixtures of cyclohexane$\mathrm{CH}_{2} \mathrm{Cl}_{2}-\mathrm{MeOH}$ (15:45:0.5, 15:45:1.5, and 15:45:3) were finally purified by RP-TLC with $\mathrm{MeOH}-\mathrm{H}_{2} \mathrm{O}$ (4:1), to yield falcatin A (1) (24.3 mg), falcatin $\mathrm{Q}(17)(4.4 \mathrm{mg})$, falcatin I (9) $(6.1 \mathrm{mg})$, and falcatin $\mathrm{L}(12)(3.7 \mathrm{mg})$. Subfraction $6 / 5$, eluted with cyclohexane-EtOAc$\mathrm{MeOH}(1: 1: 1)$, was separated further by RP-VLC with a $\mathrm{MeOH}-\mathrm{H}_{2} \mathrm{O}$ (from 1:1 to 9:1) gradient system to afford falcatin $S(19)(10.0 \mathrm{mg})$, falcatin N (14) (4.0 mg), falcatin E (5) (2.5 mg), falcatin J (10) (8.3 $\mathrm{mg}$ ), and falcatin $\mathrm{R}(\mathbf{1 8})(2.7 \mathrm{mg})$. The subfraction obtained by RP-VLC with $\mathrm{MeOH}-\mathrm{H}_{2} \mathrm{O}$ (4:1) was purified by RP-HPLC with $\mathrm{MeOH}-\mathrm{H}_{2} \mathrm{O}$ (7:3), at a flow rate of $1.0 \mathrm{~mL} / \mathrm{min}$, to afford falcatin $\mathrm{N}(14)(11.1 \mathrm{mg})$ $\left(t_{\mathrm{R}} 15.4 \mathrm{~min}\right)$ and falcatin $\mathrm{M}(13)(36.5 \mathrm{mg})\left(t_{\mathrm{R}} 19.2 \mathrm{~min}\right)$.

Falcatin A (1): amorphous solid; $[\alpha]^{25}-8\left(c 0.2, \mathrm{CHCl}_{3}\right) ;{ }^{1} \mathrm{H}$ and ${ }^{13} \mathrm{C}$ NMR data, see Tables 1 and 2; HRESIMS $m / z 677.2594[\mathrm{M}+\mathrm{Na}]^{+}$ (calcd for $\mathrm{C}_{35} \mathrm{H}_{42} \mathrm{O}_{12} \mathrm{Na}, 677.2574$ ), $672.3051\left[\mathrm{M}+\mathrm{NH}_{4}\right]^{+}$(calcd for $\left.\mathrm{C}_{35} \mathrm{H}_{46} \mathrm{NO}_{12}, 672.3020\right)$.

Falcatin B (2): amorphous solid; $[\alpha]_{\mathrm{D}}^{28}+22\left(c 0.1, \mathrm{CHCl}_{3}\right) ;{ }^{1} \mathrm{H}$ and ${ }^{13} \mathrm{C}$ NMR data, see Tables 1 and 2; HRESIMS $m / z 629.2600[\mathrm{M}+\mathrm{Na}]^{+}$ (calcd for $\mathrm{C}_{31} \mathrm{H}_{42} \mathrm{O}_{12} \mathrm{Na}, 629.2574$ ), $624.3051\left[\mathrm{M}+\mathrm{NH}_{4}\right]^{+}$(calcd for $\left.\mathrm{C}_{31} \mathrm{H}_{46} \mathrm{NO}_{12}, 624.3020\right)$.

Falcatin C (3): amorphous solid; $[\alpha]^{28}{ }_{\mathrm{D}}+13\left(c 0.1, \mathrm{CHCl}_{3}\right) ;{ }^{1} \mathrm{H}$ and ${ }^{13} \mathrm{C}$ NMR data, see Tables 1 and 2; HRESIMS $m / z 643.2756[\mathrm{M}+\mathrm{Na}]^{+}$ (calcd for $\mathrm{C}_{32} \mathrm{H}_{44} \mathrm{O}_{12} \mathrm{Na}, 643.2731$ ), 638.3211 $\left[\mathrm{M}+\mathrm{NH}_{4}\right]^{+}$(calcd for $\left.\mathrm{C}_{32} \mathrm{H}_{48} \mathrm{NO}_{12}, 638.3177\right)$.

Falcatin D (4): amorphous solid; $[\alpha]^{25}{ }_{\mathrm{D}}+16\left(c 0.1, \mathrm{CHCl}_{3}\right) ;{ }^{1} \mathrm{H}$ and ${ }^{13} \mathrm{C}$ NMR data, see Tables 1 and 2; HRESIMS $m / z 697.3256[\mathrm{M}+\mathrm{H}]^{+}$ (calcd for $\mathrm{C}_{38} \mathrm{H}_{49} \mathrm{O}_{12}, 697.3224$ ), $719.3070[\mathrm{M}+\mathrm{Na}]^{+}$(calcd for $\left.\mathrm{C}_{38} \mathrm{H}_{48} \mathrm{O}_{12} \mathrm{Na}, 719.3044\right)$.

Falcatin $E$ (5): amorphous solid; $[\alpha]^{25}{ }_{\mathrm{D}}+14\left(\right.$ c $\left.0.2, \mathrm{CHCl}_{3}\right) ;{ }^{1} \mathrm{H}$ and ${ }^{13} \mathrm{C}$ NMR data, see Tables 1 and 2; HRESIMS $m / z$ 683.3092 $[\mathrm{M}+\mathrm{H}]^{+}$ (calcd for $\mathrm{C}_{37} \mathrm{H}_{47} \mathrm{O}_{12}, 683.3068$ ), $705.2907[\mathrm{M}+\mathrm{Na}]^{+}$(calcd for $\left.\mathrm{C}_{37} \mathrm{H}_{46} \mathrm{O}_{12} \mathrm{Na}, 705.2887\right)$.

Falcatin $F$ (6): amorphous solid; $[\alpha]_{\mathrm{D}}^{25}+2\left(c 0.1, \mathrm{CHCl}_{3}\right) ;{ }^{1} \mathrm{H}$ and ${ }^{13} \mathrm{C}$ NMR data, see Tables 1 and 2; HRESIMS $m / z 691.3125[\mathrm{M}+\mathrm{Na}]^{+}$ (calcd for $\mathrm{C}_{37} \mathrm{H}_{48} \mathrm{O}_{11} \mathrm{Na}, 691.3094$ ), $686.3574\left[\mathrm{M}+\mathrm{NH}_{4}\right]^{+}$(calcd for $\left.\mathrm{C}_{37} \mathrm{H}_{52} \mathrm{NO}_{11}, 686.3540\right)$. 
Falcatin G (7): amorphous solid; $[\alpha]^{28}{ }_{\mathrm{D}}+20\left(c 0.04, \mathrm{CHCl}_{3}\right) ;{ }^{1} \mathrm{H}$ and ${ }^{13} \mathrm{C}$ NMR data, see Tables 3 and 4; HRESIMS $m / z$ 775.2986 $[\mathrm{M}+\mathrm{H}]^{+}$ (calcd for $\mathrm{C}_{42} \mathrm{H}_{47} \mathrm{O}_{14}, 775.2966$ ).

Falcatin $H$ (8): amorphous solid; $[\alpha]_{\mathrm{D}}^{28}+57\left(c 0.1, \mathrm{CHCl}_{3}\right) ;{ }^{1} \mathrm{H}$ and ${ }^{13} \mathrm{C}$ NMR data, see Tables 3 and 4; HRESIMS $m / z 701.2815[\mathrm{M}+\mathrm{Na}]^{+}$ (calcd for $\mathrm{C}_{34} \mathrm{H}_{46} \mathrm{O}_{14} \mathrm{Na}$, 701.2785), $696.3270\left[\mathrm{M}+\mathrm{NH}_{4}\right]^{+}$(calcd for $\mathrm{C}_{34} \mathrm{H}_{50} \mathrm{NO}_{14}, 696.3231$ ).

Falcatin I (9): amorphous solid; $[\alpha]_{\mathrm{D}}^{25}+63\left(c 0.1, \mathrm{CHCl}_{3}\right) ;{ }^{1} \mathrm{H}$ and

${ }^{13} \mathrm{C}$ NMR data, see Tables 3 and 4; HRESIMS $m / z 756.3264[\mathrm{M}+\mathrm{H}]^{+}$ (calcd for $\mathrm{C}_{39} \mathrm{H}_{50} \mathrm{NO}_{14}, 756.3231$ ), $778.3083[\mathrm{M}+\mathrm{Na}]^{+}$(calcd for $\left.\mathrm{C}_{39} \mathrm{H}_{49} \mathrm{NO}_{14} \mathrm{Na}, 778.3051\right)$.

Falcatin J (10): amorphous solid; $[\alpha]^{25}{ }_{\mathrm{D}}+108\left(c 0.1, \mathrm{CHCl}_{3}\right) ;{ }^{1} \mathrm{H}$ and ${ }^{13} \mathrm{C}$ NMR data, see Tables 3 and 4; HRESIMS $m / z 745.3078[\mathrm{M}+\mathrm{Na}]^{+}$ (calcd for $\mathrm{C}_{36} \mathrm{H}_{50} \mathrm{O}_{15}, 745.3047$ ).

Falcatin $\mathrm{K}(11)$ : amorphous solid; $[\alpha]_{\mathrm{D}}^{25}+77\left(c 0.1, \mathrm{CHCl}_{3}\right) ;{ }^{1} \mathrm{H}$ and ${ }^{13} \mathrm{C}$ NMR data, see Tables 3 and 4; HRESIMS $m / z 759.3240[\mathrm{M}+\mathrm{Na}]^{+}$ (calcd for $\mathrm{C}_{37} \mathrm{H}_{52} \mathrm{O}_{15} \mathrm{Na}, 759.3204$ ).

Falcatin $L$ (12): amorphous solid; $[\alpha]^{25}{ }_{\mathrm{D}}+30\left(c 0.1, \mathrm{CHCl}_{3}\right) ;{ }^{1} \mathrm{H}$ and ${ }^{13} \mathrm{C}$ NMR data, see Tables 3 and 4; HRESIMS $m / z 842.3640[\mathrm{M}+\mathrm{H}]^{+}$ (calcd for $\mathrm{C}_{43} \mathrm{H}_{56} \mathrm{NO}_{16}, 842.3599$ ), $864.3463[\mathrm{M}+\mathrm{Na}]^{+}$(calcd for $\left.\mathrm{C}_{43} \mathrm{H}_{55} \mathrm{NO}_{16} \mathrm{Na}, 864.3419\right)$.

Falcatin $M$ (13): white powder; $[\alpha]^{28}+84\left(c 0.2, \mathrm{CHCl}_{3}\right) ;{ }^{1} \mathrm{H}$ and ${ }^{13} \mathrm{C}$ NMR data, see Tables 5 and 6; HRESIMS $m / z$ 828.3479 $[\mathrm{M}+\mathrm{H}]^{+}$ (calcd for $\mathrm{C}_{42} \mathrm{H}_{54} \mathrm{NO}_{16}, 828.3443$ ), $850.3292[\mathrm{M}+\mathrm{Na}]^{+}$(calcd for $\left.\mathrm{C}_{42} \mathrm{H}_{53} \mathrm{NO}_{16} \mathrm{Na}, 850.3262\right)$.

Falcatin N (14): amorphous solid; $[\alpha]^{25}{ }_{\mathrm{D}}+53\left(c 0.1, \mathrm{CHCl}_{3}\right) ;{ }^{1} \mathrm{H}$ and ${ }^{13} \mathrm{C}$ NMR data, see Tables 5 and 6; HRESIMS $m / z 814.3333[\mathrm{M}+\mathrm{H}]^{+}$ (calcd for $\mathrm{C}_{41} \mathrm{H}_{52} \mathrm{NO}_{16}, 814.3286$ ), 836.3145 $[\mathrm{M}+\mathrm{Na}]^{+}$(calcd for $\left.\mathrm{C}_{41} \mathrm{H}_{51} \mathrm{NO}_{16} \mathrm{Na}, 836.3106\right)$.

Falcatin O (15): amorphous solid; $[\alpha]^{25}+65\left(c 0.1, \mathrm{CHCl}_{3}\right) ;{ }^{1} \mathrm{H}$ and ${ }^{13} \mathrm{C}$ NMR data, see Tables 5 and 6; HRESIMS $m / z$ 827.3479 $[\mathrm{M}+\mathrm{H}]^{+}$ (calcd for $\mathrm{C}_{43} \mathrm{H}_{55} \mathrm{O}_{16}, 827.3490$ ).

Falcatin P (16): amorphous solid; $[\alpha]^{28}-13\left(c 0.04, \mathrm{CHCl}_{3}\right) ;{ }^{1} \mathrm{H}$ and ${ }^{13} \mathrm{C}$ NMR data, see Tables 5 and 6; HRESIMS $m / z 741.3501[\mathrm{M}+$ $\mathrm{H}]^{+}$(calcd for $\mathrm{C}_{40} \mathrm{H}_{53} \mathrm{O}_{13}, 741.3486$ ).

Falcatin Q (17): amorphous solid; $[\alpha]^{25}{ }_{\mathrm{D}}-16\left(c 0.1, \mathrm{CHCl}_{3}\right) ;{ }^{1} \mathrm{H}$ and ${ }^{13} \mathrm{C}$ NMR data, see Table 5 and 6; HRESIMS $m / z$ 790.3474 $[\mathrm{M}+\mathrm{H}]^{+}$ (calcd for $\mathrm{C}_{43} \mathrm{H}_{52} \mathrm{NO}_{13}, 790.3439$ ), $812.3292[\mathrm{M}+\mathrm{Na}]^{+}$(calcd for $\mathrm{C}_{43} \mathrm{H}_{51} \mathrm{NO}_{13} \mathrm{Na}$, 812.3258).

Falcatin $R$ (18): amorphous solid; $[\alpha]^{25}-18\left(c 0.2, \mathrm{CHCl}_{3}\right) ;{ }^{1} \mathrm{H}$ and ${ }^{13} \mathrm{C}$ NMR data, see Tables 6 and 7; HRESIMS $m / z 776.3316[\mathrm{M}+\mathrm{H}]^{+}$ (calcd for $\left.\mathrm{C}_{42} \mathrm{H}_{50} \mathrm{NO}_{13}, 776.3282\right), 798.3129[\mathrm{M}+\mathrm{Na}]^{+}$(calcd for $\left.\mathrm{C}_{42} \mathrm{H}_{49} \mathrm{NO}_{13} \mathrm{Na}, 798.3102\right)$.

Falcatin S (19): amorphous solid; $[\alpha]^{25}-23\left(c 0.1, \mathrm{CHCl}_{3}\right) ;{ }^{1} \mathrm{H}$ and ${ }^{13} \mathrm{C}$ NMR data, see Tables 6 and 7; HRESIMS $m / z 748.3373[\mathrm{M}+\mathrm{H}]^{+}$ (calcd for $\mathrm{C}_{41} \mathrm{H}_{50} \mathrm{NO}_{12}, 748.3333$ ), $770.3186[\mathrm{M}+\mathrm{Na}]^{+}$(calcd for $\left.\mathrm{C}_{41} \mathrm{H}_{49} \mathrm{NO}_{12} \mathrm{Na}, 770.3152\right)$.

Euphorprolitherin $D$ (20): amorphous solid; $[\alpha]_{D}^{25}+74(c) 0.1$, $\left.\mathrm{CHCl}_{3}\right) ;{ }^{1} \mathrm{H}$ and ${ }^{13} \mathrm{C}$ NMR data identical with published data. ${ }^{33}$

Electrophysiological Investigations. GIRK and hERG ion currents were measured using planar patch-clamp technology with a four-channel medium throughput fully automated patch-clamp system (Patchliner, Nanion Technologies GmbH, Munich, Germany). ${ }^{47}$ Whole-cell configuration was applied in all experiments. The pipetting protocols were controlled by PatchControlHT 1.07.50 software (Nanion Technologies $\mathrm{GmbH}$ ). Current recordings and online analysis were performed with an EPC-10 Quadro patch-clamp amplifier (HEKA Elektronik Dr. Schulze GmbH) using the PatchMaster 2.43 software (HEKA Elektronik Dr. Schulze GmbH, Lambrecht/Pfalz, Germany).

Automated patch-clamp experiments were carried out at room temperature with a suspension of stable transfected cell lines. Suspensions of cells for measurements were derived from running cell cultures. Cells were maintained in an incubator at $37{ }^{\circ} \mathrm{C}$, in $5 \% \mathrm{CO}_{2}$. Before experiments, cells were washed twice with PBS (Life Technologies Corporation, Carlsbad, CA, USA) and then detached with trypsin-EDTA (PAA Laboratories GmbH, Pasching, Austria) for 1-3 min. Trypsin was blocked with serum containing complete culture medium. The cell suspension was next centrifuged $(2 \mathrm{~min}, 100 \mathrm{~g})$, resuspended in serum-free base medium at a final density of $1 \times 10^{6}-5 \times$
$10^{6}$ cells $/ \mathrm{mL}$, and kept in the cell hotel of the Patchliner system. Cells were recovered after 15-30 min and remained suitable for automated patch-clamp recordings for up to $4 \mathrm{~h}$.

Stocks of extra- and intracellular solutions were made for automated patch-clamp recordings. Chemicals were purchased from Sigma-Aldrich Corporation (St. Louis, MO, USA). All solutions were sterile filtered. Aliquots were stored at $-20{ }^{\circ} \mathrm{C}$ and warmed to room temperature before use.

For each diterpene isolated from E. falcata, a stock solution of test compound $(10 \mathrm{mM})$ was prepared. The solubilizing agent was dimethyl sulfoxide (DMSO, Sigma-Aldrich Corporation). Aliquots were stored at $-20{ }^{\circ} \mathrm{C}$. Before experiments, stock solutions were further diluted with high $\mathrm{K}^{+}$external solution (GIRK assay) or external solution (hERG assay) to give appropriate concentrations for the measurements. The final DMSO concentrations in the tested samples were $0.3 \%$ or less.

GIRK Channel Inhibitory Assay. Experiments were carried out on HEK-293 (human embryonic kidney) cells stably expressing GIRK1/4 (Kir3.1/3.4) $\mathrm{K}^{+}$channels. $^{48}$ This cell line originated from UCL Business PLC (London, UK). Cells were maintained in MEM (PAA Laboratories $\mathrm{GmbH}$ ) medium supplemented with 10\% FBS (fetal bovine serum) (PAA Laboratories $\mathrm{GmbH}$ ) and $182 \mu \mathrm{g} / \mathrm{mL}$ zeocin (Life Technologies Corporation).

The following solutions were used during patch-clamp recordings (compositions in $\mathrm{mM}$ ): external solution: $\mathrm{NaCl} \mathrm{140,} \mathrm{KCl} 4$, glucosemonohydrate 5, $\mathrm{MgCl}_{2} 1, \mathrm{CaCl}_{2}$ 3, and HEPES 10 ( $\left.\mathrm{pH} 7.4, \mathrm{NaOH}\right)$; high $\mathrm{K}^{+}$external solution: $\mathrm{NaCl} 135, \mathrm{KCl} 25, \mathrm{MgCl}_{2} 1, \mathrm{CaCl}_{2} 3$, and HEPES 10 ( $\mathrm{pH} 7.4, \mathrm{NaOH})$; $\mathrm{K}^{+}$-free external solution: $\mathrm{NaCl} 160$, $\mathrm{MgCl}_{2} 1, \mathrm{CaCl}_{2}$ 3, and HEPES $10(\mathrm{pH} 7.4, \mathrm{NaOH})$; internal solution: $\mathrm{K}-$ gluconate 40, $\mathrm{NaCl} 20, \mathrm{KF} 60$, EGTA 20, and HEPES 10 (pH 7.2, $\mathrm{KOH}$ ), supplemented with $0.9 \mathrm{mM} \mathrm{GTP} \gamma \mathrm{S}$ (guanosine $5^{\prime}-\mathrm{O}-(\gamma$ thio)triphosphate) before the experiments to induce channel activation.

The voltage protocol for the GIRK ion channel assay (see inset in panel C, Figure 6) started with a depolarizing voltage step to $60 \mathrm{mV}$ for $100 \mathrm{~ms}$ before a $500 \mathrm{~ms}$ long hyperpolarizing ramp to $-140 \mathrm{mV}$ was applied. Then, the membrane potential remained at $-140 \mathrm{mV}$ for 100 $\mathrm{ms}$ before returning to the holding potential of $-40 \mathrm{mV}$. The inward currents were calculated from the $-140 \mathrm{mV}$ segment. The pulse frequency was approximately $0.1 \mathrm{~Hz}$.

At the beginning of the recordings, the normal external solution (4 $\mathrm{mM} \mathrm{K} \mathrm{K}^{+}$) was replaced with a high- $\mathrm{K}^{+}$external solution in order to increase the current amplitude. After $3 \mathrm{~min}$ of a control period, the test compounds were added to the cells in increasing concentrations ( 1 and $10 \mu \mathrm{M}$ in the case of screening; $1,3,10$, and $30 \mu \mathrm{M}$ for each $\mathrm{IC}_{50}$ assay), for approximately $2 \mathrm{~min}$. Propafenone $(1 \mu \mathrm{M}$, Sigma-Aldrich Corporation) was used as a reference compound, and then potassiumfree external solution was applied. The data were corrected with the current values measured in the potassium-free external solution, which served as the baseline.

hERG Channel Inhibitory Assay. hERG measurements were performed on HEK-293 cells stably transfected with cDNA encoding the hERG (Kv11.1) K $\mathrm{K}^{+}$channel. ${ }^{49}$ The cell line was purchased from Cell Culture Service (Hamburg, Germany). Cells were maintained in IMDM (Iscove's modified Dulbecco's medium) (PAA Laboratories GmbH) medium supplemented with $10 \%$ FBS (PAA Laboratories $\mathrm{GmbH}$ ), 2 $\mathrm{mM}$ L-glutamine (Life Technologies Corporation), $1 \mathrm{mM}$ Na-pyruvate (PAA Laboratories $\mathrm{GmbH}$ ), and $500 \mu \mathrm{g} / \mathrm{mL}$ G418 (PAA Laboratories $\mathrm{GmbH})$.

The following solutions were used during patch-clamp experiments (compositions in $\mathrm{mM}$ ): external solution: $\mathrm{NaCl} \mathrm{140,} \mathrm{KCl} \mathrm{4}$, glucosemonohydrate 5, $\mathrm{MgCl}_{2} 1, \mathrm{CaCl}_{2} 3$, and HEPES 10 (pH 7.4, $\mathrm{NaOH}$ ); internal solution: $\mathrm{KCl} \mathrm{50,} \mathrm{NaCl} 10, \mathrm{KF} 60$, EGTA 20, and HEPES 10 ( $\mathrm{pH} 7.2, \mathrm{KOH})$.

The voltage protocol for the hERG ion channel (see inset in panel A, Figure 6) started with a short $(100 \mathrm{~ms})-40 \mathrm{mV}$ voltage step, as a reference. A $20 \mathrm{mV}$ depolarizing step was applied for $3 \mathrm{~s}$, and then the test potential was $-40 \mathrm{mV}$ for $1 \mathrm{~s}$ to evoke an outward tail current. The holding potential was $-80 \mathrm{mV}$, and the pulse frequency was $0.1 \mathrm{~Hz}$. The peak tail current was corrected with the leak current defined during the first period to $-40 \mathrm{mV}$. 
The recording started in the external solution. After this control period, increasing concentrations of each test compound (3, 10, and 30 $\mu \mathrm{M}$, respectively) were applied, each for approximately $3 \mathrm{~min}$. Following test compound administration, $10 \mu \mathrm{M}$ amitriptyline was applied as a reference inhibitor followed by a wash-out step.

\section{ASSOCIATED CONTENT}

\section{S Supporting Information}

The Supporting Information is available free of charge on the ACS Publications website at DOI: 10.1021/acs.jnatprod.6b00260.

Representative 1D and 2D NMR spectra of the diterpenes isolated from Euphorbia falcata illustrating myrsinane-, cyclomyrsinane-, and premyrsinane-type polyesters (PDF)

\section{AUTHOR INFORMATION}

\section{Corresponding Author}

*Tel: +36-62-546453. Fax: +36-62-547404. E-mail: hohmann@ pharm.u-szeged.hu.

\section{Notes}

The authors declare no competing financial interest.

\section{ACKNOWLEDGMENTS}

Financial support from the Hungarian Scientific Research Fund (OTKA K109846) is gratefully acknowledged. A.V. acknowledges the award of a János Bolyai scholarship of the Hungarian Academy of Sciences.

\section{REFERENCES}

(1) http://apps.who.int/iris/bitstream/10665/200009/1/ 9789241565110 eng.pdf.

(2) Dunlop, J.; Bowlby, M.; Peri, R.; Vasilyev, D.; Arias, R. Nat. Rev. Drug Discovery 2008, 7, 358-368.

(3) Farre, C.; Stoelzle, S.; Haarmann, C.; George, M.; Brüggemann, A.; Fertig, N. Expert Opin. Ther. Targets 2007, 11, 557-565.

(4) Farre, C.; Fertig, N. Expert Opin. Drug Discovery 2012, 7, 515-524.

(5) Farre, C.; Haythornthwaite, A.; Haarmann, C.; Stoelzle, S.; Kreir, M.; George, M.; Brüggemann, A.; Fertig, N. Comb. Chem. High Throughput Screening 2009, 12, 24-37.

(6) Lü, Q.; An, W. F. Comb. Chem. High Throughput Screening 2008, 11, 185-194.

(7) Stoelzle, S.; Obergrussberger, A.; Brüggemann, A.; Haarmann, C.; George, M.; Kettenhofen, R.; Fertig, N. Front. Pharmacol. 2011, 2, Article 76, 1-11.

(8) Zheng, W.; Spencer, R. H.; Kiss, L. Assay Drug Dev. Technol. 2004, 2, 543-552.

(9) Priest, B. T.; Swensen, A. M.; McManus, O. B. Curr. Pharm. Des. 2007, 13, 2325-2337.

(10) Willumsen, N. J.; Bech, M.; Olesen, S.-P.; Jensen, B. S.; Korsgaard, M. P. G.; Christophersen, P. Recept. Channels 2003, 9, 3-12.

(11) Dabrowski, M. A.; Dekermendjian, K.; Lund, P.-E.; Krupp, J. J.; Sinclair, J.; Larsson, O. CNS Neurol. Disord.: Drug Targets 2008, 7, 122128.

(12) Treherne, J. M. Curr. Pharm. Des. 2006, 12, 397-406.

(13) Walsh, K. B. Front. Pharmacol. 2011, 2, Article 64, 1-8.10.3389/ fphar.2011.00064

(14) Dobrev, D.; Friedrich, A.; Voigt, N.; Jost, N.; Wettwer, E.; Christ, T.; Knaut, M.; Ravens, U. Circulation 2005, 112, 3697-3706.

(15) Hashimoto, N.; Yamashita, T.; Tsuruzoe, N. Pharmacol. Res. 2006, 54, 136-141.

(16) Kobayashi, T.; Ikeda, K. Curr. Pharm. Des. 2006, 12, 4513-4523.

(17) Sanguinetti, M. C.; Tristani-Firouzi, M. Nature 2006, 440, 463469.
(18) Farre, C.; George, M.; Brüggemann, A.; Fertig, N. Drug Discovery Today: Technol. 2008, 5, e23-e28.

(19) Abi-Gerges, N.; Holkham, H.; Jones, E. M. C.; Pollard, C. E.; Valentin, J.-P.; Robertson, G. A. Br. J. Pharmacol. 2011, 164, 419-432.

(20) Polonchuk, L. Front. Pharmacol. 2012, 3, Article 3, 1-7.10.3389/ fphar.2012.00003

(21) Vasanthi, H. R.; ShriShriMal, N.; Das, D. K. Curr. Med. Chem. 2012, 19, 2242-2251.

(22) Vasas, A.; Hohmann, J. Chem. Rev. 2014, 114, 8579-8612.

(23) Xu, Z. H.; Sun, J.; Xu, R. S.; Qui, G. W. Phytochemistry 1998, 49, $149-151$.

(24) Corea, G.; Fattorusso, E.; Lanzotti, V.; Taglialatela-Scafati, O.; Appendino, G.; Ballero, M.; Simon, P. N.; Dumontet, C.; Di Pietro, A. J. Med. Chem. 2003, 46, 3395-3402.

(25) Vasas, A.; Sulyok, E.; Martins, A.; Rédei, D.; Forgo, P.; Kele, Z.; Zupkó, I.; Molnár, J.; Pinke, G.; Hohmann, J. Tetrahedron 2012, 68, $1280-1285$.

(26) Sulyok, E.; Vasas, A.; Rédei, D.; Forgo, P.; Kele, Z.; Pinke, G.; Hohmann, J. Tetrahedron 2011, 67, 7289-7293.

(27) Xu, J.; Yang, B.; Fang, L.; Wang, S.; Guo, Y.; Yamakuni, T.; Ohizumi, Y. J. Nat. Med. 2013, 67, 333-338.

(28) Li, J.; Xu, L.; Wang, F. P. Helv. Chim. Acta 2010, 93, 746-752.

(29) Xu, J.; Guo, Y.; Xie, C.; Li, Y.; Gao, J.; Zhang, T.; Hou, W.; Fang, L.; Gui, L. J. Nat. Prod. 2011, 74, 2224-2230.

(30) Ahmad, V. U.; Hussain, H.; Jassbi, A. R.; Hussain, J.; Bukhari, I. A.; Yasin, A.; Aziz, N.; Choudhary, M. I. J. Nat. Prod. 2003, 66, 1221-1224.

(31) Abbas, M.; Jassbi, A. R.; Zahid, M.; Ali, Z.; Alam, N.; Akhtar, F.; Choudhary, M. I.; Ahmad, V. U. Helv. Chim. Acta 2000, 83, 2751-2755.

(32) Ahmad, V. U.; Hussain, J.; Hussain, H.; Jassbi, A. R.; Ullah, F.; Lodhi, M. A.; Yasin, A.; Choudhary, M. I. Chem. Pharm. Bull. 2003, 51, 719-723.

(33) Zhang, W. J.; Chen, D. F.; Hou, A. J. Chin. J. Chem. 2004, 22, $103-$ 108.

(34) Jeske, F.; Jakupovic, J.; Berendsohn, W. Phytochemistry 1995, 40, $1743-1750$

(35) Shi, Q. W.; Su, X. H.; Kiyota, H. Chem. Rev. 2008, 108, 4295-327. (36) Ghanadian, S. M.; Ayatollahi, A. M.; Mesaik, M. A.; Abdalla, O. M. Nat. Prod. Res. 2013, 27, 246-254.

(37) Ghanadian, M.; Choudhary, M. I.; Ayatollahi, A. M.; Mesaik, M. A.; Abdalla, O. M.; Afsharypour, S. J. Asian Nat. Prod. Res. 2013, 15, $22-$ 29.

(38) Ghanadian, S. M.; Ayatollahi, A. M.; Afsharypuor, S.; Javanmard, S. H.; Dana, N. J. Nat. Med. 2013, 67, 327-332.

(39) Shokoohinia, Y.; Sajjadi, S. E.; Zolfaghari, B.; Chianese, G.; Appendino, G.; Taglialatela-Scafati, O. Fitoterapia 2010, 81, 884-890.

(40) Xu, J.; Jin, D.; Song, H.; Guo, Y.; He, Y. Fitoterapia 2012, 83, $1205-1209$.

(41) Wu, D. G.; Sorg, B.; Hecker, E. Phytother. Res. 1994, 8, 95-99.

(42) Ayatollahi, A. M.; Ghanadian, M.; Mesaik, A.; Abdella, O. M.; Afsharypuor, S.; Kobarfard, F.; Mirza-Taheri, M. J. Asian Nat. Prod. Res. 2010, 12, 1020-1025.

(43) Yu, J.; Jin, D.; Guo, P.; Xie, C.; Fang, L.; Guo, Y. Molecules 2012, $17,9520-9528$.

(44) Xu, J.; Guo, Y.; Xie, C.; Li, Y.; Gao, J.; Zhang, T.; Hou, W.; Fang, L.; Gui, L. J. Nat. Prod. 2011, 74, 2224-2230.

(45) Xu, J.; Jin, D.; Guo, Y.; Xie, C.; Ma, Y.; Yamakuni, T.; Ohizumi, Y. Bioorg. Med. Chem. Lett. 2012, 22, 3612-3618.

(46) Li, J.; Xu, L.; Wang, F. P. Helv. Chim. Acta 2010, 93, 746-752.

(47) http://nanion.de/images/stories/pdf/patchliner.pdf.

(48) Lajter, I.; Vasas, A.; Orvos, P.; Bánsághi, S.; Tálosi, L.; Jakab, G.; Béni, Z.; Háda, V.; Forgo, P.; Hohmann, J. Planta Med. 2013, 79, 17361741.

(49) Orvos, P.; Virág, L.; Tálosi, L.; Hajdú, Z.; Csupor, D.; Jedlinszki, N.; Szél, T.; Varró, A.; Hohmann, J. Fitoterapia 2015, 100, 156-165. 